\title{
Dynamic Optimization of Job Distribution on Machine Tools Using Time Decomposition into Constant Job-Mix Stages
}

\author{
by \\ Subramanian Natarajan \\ Department of Mechanical Engineering \\ McGill University \\ Montréal, Canada
}

March, 1992

A thesis submitted to the Faculty of Graduate Studies and Research in partial fulfilment of the requirements for the degcee of Master of Engineering

(C) S. Natarajan, March 1992 
To Amma \& Appa...

With Respect, Gratitude and Admiration

for all they have :sone. 


\begin{abstract}
This thesis deals with the development, analysis and application of a new method to optimize the allocation of jobs on machine tools. 'The bencfits of this mothorl are derived through time-decomposition of the scheduling horizon.

The decompcsition scheme is based on the scheduled flow of jobs i.c., the input of jobs to the shop floor and their departure after processing. The partitioning procedure divides the planning horizon into 'stages', or time periods, at which the job-mix remains consiant. The optimization of job allocation is carried out within each partition and successive stages are treated sequentially. The dynamic nature of the problem is such that the solution at a stage affects the boundary conditions of the subsequent stage. The Constant Job-Mix Stage (CMS) algorithm developed to solve the job allocation problem, accounts for the setup times and enables one to obtain integer solutions whilc reducing slack on machines and enforcing due date on jobs.

The application of the algorithm is demonstrated for three different cases. The first two cases focus on single operation jobs and represent two different approaches to scheduling. The former is concerned with scheduling jobs from starting times illustrating 'push' system while the latter is due date driven, representing a 'pull' system which corresponds to the just-in-time (JIT) philosophy. The third case deals with the assignment of multiple operation jobs to machine tools which are grouped according to processes. The results indicate that the optimization based on the constant job-mix stages, leads to increased utilization of machine tools, higher production rate, with shorter makespan of individlual jobs and reduced computational time.

The possibility of interfacing the CMS algorithm with the other components of manufacturing systems is also discussed. The opportunities for the cnlancement of integrated intelligent systems, through open and lecdback loops are pointed out.
\end{abstract}




\section{Résumé}

C'ctle thè !raite du développement, de l'aralyse, et de l'application d'une nouvelle méthode pour optimiser la répartıtion de tâches sur des machines-outils. Las avantages de cette méthode proviennent de la décomposition temporelle du calendricr de planification.

Lo plan de décomposition est basé sur le flux planifié des tâches, c'est-à-dirc sur l'arrivée de tâches dans l'atelier et leur départ une fois accomplies. Lc processus de fractionnenont divise le calendrier en étapes ou intervals de temps pendant lesquelles le job-mix reste constant. L'optimisation de la répartition des tâches s'offectue au sein de chaque fraction et les étapes successives sont traitées de façon sćquentielle. La nature dynamique du problème est telle que la solution adonptéc à une étape affecte les conditions aux limites de l'étape suivante. L'algorithme CMS ( Constant Job-Mix Stage) développé pour rćsoudre le problème de répartition de táches tient compte des temps d'installation et permet d'obtenir des solutions entiòres tout en réduisant les temps-morts des machines et en assurant l'accomplissement des tâches avant leur date d'échéance.

L'algorithme peut s'appliquer dans trois cas differents. Les deux premiers cas ne concernent que les tâches ne comportant qu'une opération et représentent deux approches différentes de planification. Le premier concerne la planification des tâches à partir des temps de départ, illustrant le système "push", alors que le sccond est basé sur la date d'échéance, représentant un système "pull "qui correspond au princıpe du Juste-à-Temps. Le troisième cas traite de l'affectation de différentes tâches sur des machines-outils regroupées par procédé. Les résultats montrent que l'optimisation basée sur les étapes à job-mix constant conduit à un taux de production plus élevé avec un temps total d'accomplissement de chaque tâche plus court cl un temps de calcul moins ime ortant.

La question de la communication entre l'algorithme CMS et d'autres composantes du système de production est traitće aussi. Les possibilités de renforcer les sy'stèmes intelligents intégrés grâce à des boucles ouvertes et des boucles fermées sont également discutées. 


\section{Statement of Originality and Contribution to Knowledge}

The anthor of this thesis claims originality for the developtrent of the follewing roncepts:

- The development of a new method to partition the seledulung hencon the scheme is based on the scheduled flow of johs, theit inpul and ont put fiom the shop floor, such that the partitions have const ant jol-mis.

- The dynamic optimization priuciple The optimisation procedune mosen from one stage, to the next providing a link between the stigen, cypung the dynamir nature of the problem.

The constant job-mix stage (CMS) algotithm developed on the hasin ol the above two concepts, is constnuer as an original contribution to the fichl of pho duction systems. This algorithm enables one to obtain intrger solutums, terluce., slack on machines and enforces due dates on jobs. An equalion in derivend to rompute the computational time savings when CNS algorthm is applierl for ungle and multiple operation jobs, in comparison with aggregaterl approarih. 


\section{Acknow!edgements}

The authon whines to express his sincere gratitude and appreciation to his resouch snpervinor, l'rof. L. Kops, for his thoughtful suggestions and constructive guilduce which contributed to the present study. and for his continuous cncouragement, thronghout the course of this work.

Sincere thanks to Dr. Miched Mizrach, RAFAEL, Isracl (on sabbatic leave al M, (iill Iniversity) for fruitful discussions on various aspects of this research.

The work presented in this thesis was conducted under the support of the Nalural Sciences and Engineering Research Council of Canada which the author gratly appreciates. 


\section{Contents}

Abstract

Résumé

Statement of Originality and Contribution to Knowledge iii

Acknowledgements iv

Table of Contents v v

List of Figures viii

List of Tables $x$

List of Notations $\quad$ xii

1 Introduction 1

1.1 General Remarks . . . . . . . . . . . . . . . . I

1.2 Motivation for the Study . . . . . . . . . . . .

1.3 Thesis Outline $\ldots \ldots \ldots \ldots \ldots \ldots \ldots \ldots$ 
2 Job Allocation - State of the Art Review 9

2.1 Litenature Reriew of Studies on Job Alloration . . . . . . !

22 The wohk of M. Alaee at McCill University . . . . . . . . 133

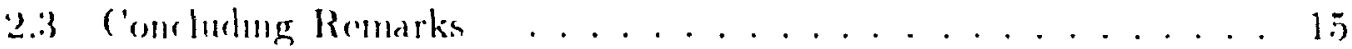

3 Time Decomposition and Dynamic Optimization 17

31 Neressity for Decomposition ................ 17

32 Time Deromposition Scheme. . . . . . . . . . . . . 19

3.3 Dýnamir Optimization Pranciple............. 22

4 The Job Allocation Algorithm 24

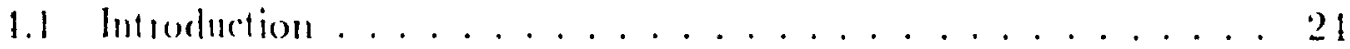

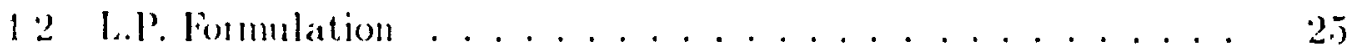

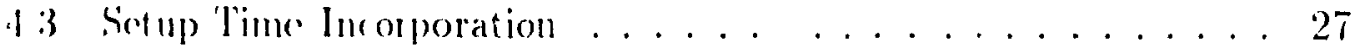

I I Other Functions of the Agorithm .............. 28

15 Agorithm Procedure .................... 29

5 Application of A Jgorithm to Single Operation Job Shops 33

5.1 Analysis of the Problem ................. 33

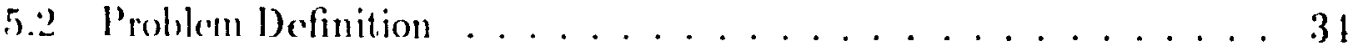

5.3 Scheduling from the Starting Times . . . . . . . . . . 35

5.3 .1 Numcrical Example . . . . . . . . . . . . . 35

5.3 .2 Results and Discussion . . . . . . . . . . . 40

5.4 Scheduling from the Completion Times . . . . . . . . . . 42 
†.1.1 Kumerical Example... . . . . 11

.52 Results and Discussum . . . . . . . . 19

6 Application of Algorithm to Multiple Operation Job Shops 58

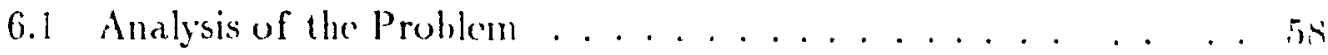

62 L.P. Formulation . . . . . . . . . . . . . 5?

6.3 Solution Procedure ..................... (1)

6.4 Numerical Example................... (i)

6.5 Results and Discussion .................. . (i)

7 Integration in Intelligent Manufacturing Systems

8 Conclusions and Recommendations for Further Study 78

8.1 Conclusions .........................

8.2 Recommendations for Further Study .............. . \&l

$\begin{array}{ll}\text { Bibliography } & 81\end{array}$

A Sample of Job Control and Data Cards for MPSX 90

B Sample of Computational Results $\quad \mathbf{9 4}$

vii 


\section{List of Figures}

31 Pictorial representation of timc-decemposition based on job arrixal

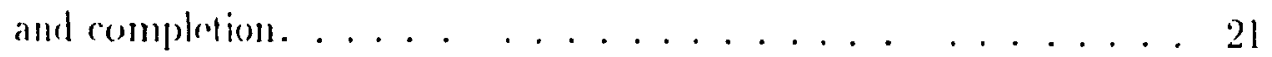

5.1 Allocation of jobs on machine tools based on Aggregaterl approach and siage approach . . . . . . . . . . . . 41

5.2 Jol) arriakls (SPT), late starts (CMS) due times and stages . . .5.5

5.3 Job allocation pattern determined by: (a) SPT rule, and (b) CMS

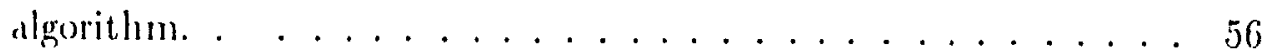

5.1 Starts and makespans of jobs determined by SPT rule anrl CMS algonthm. . . . . . . . . . . . . . 57

6.I Flow chart for the solution procedure . . . . . . . . 63

6.2 Allocation of jobs at section \# 1 determined by SPT rule and ('MS algorithm. . . . . . . . . . . . . 71

6..) (iantl chart representing the flow of job $A$ and job F for SPT rule

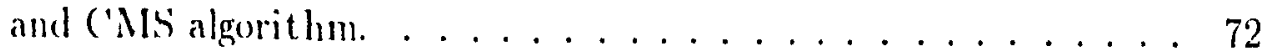


6.4 Completion dates and makespans of johs resultung from Sil rolle and CMS algorithm. ....................... . . . . . 


\section{List of Tables}

5.1 Processing times of jobs (example 5.3) $\ldots \ldots \ldots \ldots$

5.2 Demand quantities, arrival and due dates (example 5.3 ) . . . 37

5.3 Availability of machine tools (example 5.3$) \ldots \ldots \ldots \ldots$

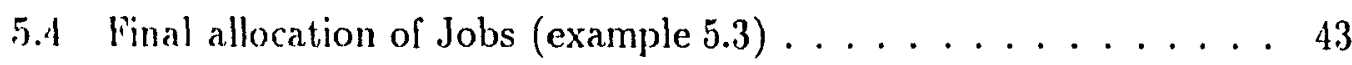

5.5 Comparison of completion time and makcspan (example 5.3) . . 43

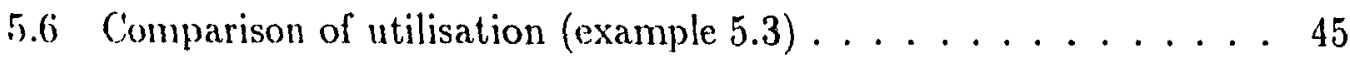

5.7 Processing times of jobs (example 5.4$) \ldots \ldots \ldots 47$

5.8 Setup times of jobs on machines (example 5.4 ) . . . . . 47

5.9 Demand quantities and due dates (example 5.4) $\ldots \ldots \ldots 48$

5.10 Comparison of late start times (example 5.4$) \ldots \ldots \ldots$

5.11 Comparison of utilisation (example 5.4$) \ldots \ldots \ldots \ldots 3$

5.12 Comparison of frce capacity (example 5.4$) \ldots \ldots \ldots$

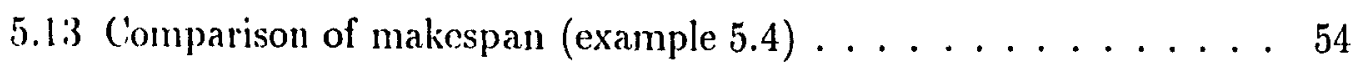

6.1 Processing times of jobs on machine tools (exämple 6.4) . . . . 65

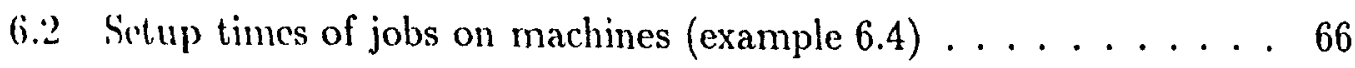


6.3 Demand quantities and due dates (example 6.1) ....... (ii

6.4 Comparison of machine utilization (example 6.1 ) . . . . . . 69)

6.5 Comparison of completion dates and makespans (examplo 6.1) . . T0

6.6 Comparison of production rate $($ cxample 6.4$) \ldots \ldots . . . . .70$ 


\section{List of Notations}

$\jmath=$ Type of component (job), $j=A, B, \ldots, N$

$\iota=$ Stages or time periods, $i=1,2, \ldots, P$

$m=$ Type of machines, $m=1,2, \ldots, M$

$l=$ Index for sections (operations) $, l=1,2, \ldots, L$

$r_{\imath m}=$ Machine availability index

$r_{m m}= \begin{cases}1 & \text { if machine } m \text { is available at stage } ~ \\ 0 & \text { otherwise }\end{cases}$

$s_{j m}=$ Processing capability index

$s_{\jmath m}= \begin{cases}1 & \text { if machine } m \text { is capable of processing job } \jmath \\ 0 & \text { otherwise }\end{cases}$

$X_{t \jmath m}=$ Quantily of job $j$ manufactured at stage $\imath$ and at machine $m$

$Q_{j}=$ Quantity of job $j$ to be processed

$T_{\imath m}=$ Time available at work center $m$ during the stage $i$

$R_{y m}=$ Processing time of job $j$ on machine $m$

$S_{j m}=$ Setup time of job $j$ on machine $m$

$X_{\imath \jmath m l}=Q$ Qty. of job $j$ manufactured during stage $i$ at machine $m$ on section $l$

$T_{i m l}=$ Time available at machine $m$ on section $l$ during the stage $i$ 
$R_{\jmath m l}=$ Processing time of job $\jmath$ on machine $m$ at section $l$

$S_{j m l}^{\prime}=$ Setup time of job $j$ on machine $m$ at section $l$

$r_{\imath m l}=$ Machine availability index

$r_{m m l}= \begin{cases}1 & \text { if machine } m \text { at section } l \text { is available during stage } ~ \\ 0 \text { otherwise }\end{cases}$

$s_{2 \cdot n l}=$ Processing capability index

$s_{\partial m l}= \begin{cases}1 & \text { if machine } m \text { at section } l \text { is capable of processing jol, }, \\ 0 & \text { otherwise }\end{cases}$ 


\section{Chapter 1}

\section{Introduction}

\subsection{General Remarks}

Job allocation decision is a very important activity in the production planning function of a manufacturing environment. It has particular implications to the machine tool utilization, factory efficiency, product quality and ability to meet duc dates.

Because of their sensitivity to various performance measures, job allocation decisions are quite complex. Several methods and procedures are being developed to mect this challenging problem. As a result, there are a variety of solutions suggested, each analysing the problem from different perspectives and with different degrees of complexity. These procedures involve substantial amount of mathematical calculations and the use of computers help to a large extent in the development and application of solutions. Yet job allocation is one major 
function which has not taken fuli advantage of computerization in a manufacturing system. The current research in this area includes not only optinizing the job allocation function, but also integrating the other components of the manufacturing system with this function.

Job distribution on machine tools is a short, range capacity decision assigning jobs, activities or tasks to available resources (machine tools). The result of this process is a timetable which describes exactly where and how much of each task should be performed. In addition, the schedule details regarding the commencement of each task and its duration, serve to obtain a better knowledge of the flow of jobs on the shop floor. The process of job allocation helps to provide production control by determining the load on machine tools and hence to identify the bottlenecks on the shop floor.

In the production planning function, job allocation should be clearly differentiated from job sequencing as the term 'scheduling' is often used to represent both these activities. The purpose of job allocation is to distribute jobs on machine tools such that the available capacity (of the machine tools) is efficiently and effectively used. The purpose of sequencing is to determine the order in which the jobs or tasks have to be performed on a machine tool in order to best satisfy some criteria like minimum makespan of jobs, minimum tardiness, ctc. The job distribution function being an allocation decision, uses the information made available by the aggregate planning and facilities planning. This involves ıning for all production line over approximately one year ahead. Thus, job- 
resource allocation is the most constrained decision in the hierarchy of capacity planning decisions.

Conflicting objectives are often the characteristics of job allocation decisions: high efficiency, low inventory and completion of all the tasks or jobs wi.hin the due dates to ensure prompt customer service. Efficiency is achieved by a job allocation schedule which maintains high utilization of labour, equipment (macline tools) and space. Of course the schedule should seek to maintain low inventories, which may lead to low efficiency due to lack of available matcrial for processing, or high setup times. Thus a trade-off decision in job allocation function between high efficiency and low inventory level is required. The primary aim of job-resource allocation decision is, therefore, to make a balance between conflicting objectives so as to arrive at a satisfactory performance of the overall manufacturing system.

Job allocation is not only influenced by several factors, but also highly dependant upon the decisions made elsewhere in the plant. Apart from these decisions, various factors constrain it by adding complexity. As a result, existing job allocation problem solution procedures are sub-optimal. This is because (1) the factors which influence the decision process are simplified in order to reduce the complexity (e.g., setup times being considered as a part of processing times) and (2) the dimensions of the problem are reduced so that a computational solution is feasible. These approximations often produce unrealistic, unsatisfactory solutions. Therefore the importance of developing a simple, computable but realistic 
general solution procedure must be emphasized.

Since the job allocation function also mfluences several other components of the manufacturing system, it is imperative that if povides the most fovomable conditions for the other activities. In this context, an optimum solution fon job allocation is desired for a specific performance criteriat. In exinting puocedures the search for optimum job allocation is the main canse of difficulties in compulational solution. Thus the increase in complexity of job allocation problems leade to sub-optimal solutions. Ilowever, reasonable approximation is anceptable because optimal job allocation is difficult, often impossible. In mont circumstrueses, the optimization tools ate combined with a set of mos. Sinch a procedure pueduces acceptable results while meeting the defined critein.

\subsection{Motivation for the Study}

The job distribution function helps in several aspects of decinion making. It aids in determining the type and amount of resource (machine fools) repuincment, additional capacity needed and thereby to identify the bot telenecks. It is essential that the job distribution in a manufacturing system is canjed ont efficiontly because in many circumstances the necessity to procure arlditional feriliticu an be postponed by efficient loading of existing machine tools.

While scheduling problems of varying degrees of importaner orcur in all types of systems, they are particularly complex in job shops. A job shop is a process. 
For need production system that employs general purpose machine tools. Sometimes, in an open shop, production is commenced based on custoners' orders. At other times, in the case of closed shops, it is based on inventory replenishment derisions. In a job shop a large number of different products are processed, cach in a sperifir lot sizes. First rome first served, random selection and other priority rules to load jobs on machines may not be applicable for all situations and sometimes they will prove unacceptable. This will result in delayed deliveries and unbalanced utilization of resources. A clear understanding of the job allocation procedures at the most detailed level will help to alleviate these difficulties.

Job shops are characterized by the variety of jobs that has to be processed on limited resources and the set of tasks performed on each component differs widely. This leads to an increase in the dimension of the problem when optimization is attempted using tools like linear (L.P.), or other mathematical programming. Morcover in many situations the time and cost parameters governing the problem are assumed to be constant over the entire scheduling horizon. This is unrealistic esperially when the horizon spans a long period. Hence it is imperative that a new procedure be developed to partition these problems such that the random changes in the variables are accommodated. In a job shop, setup times are significant due to the variety of jobs that are processed and the schedule is dymamically asynchronous because jobs have different arrival and completion times. An efficient job allocation procedure should address these issues apart from optimizing the assignment. 


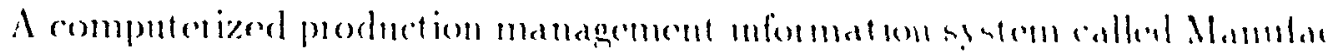

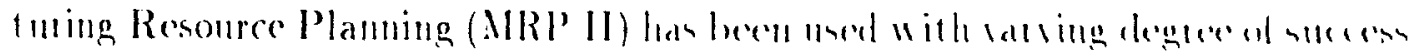

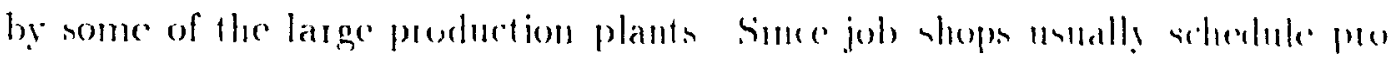

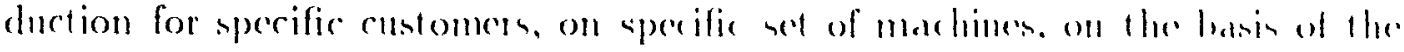

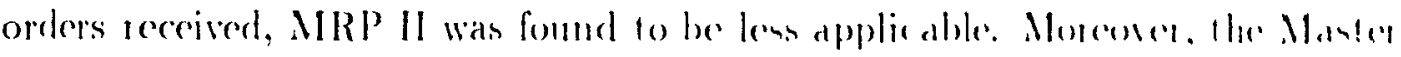

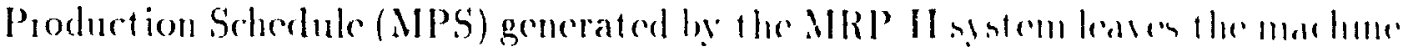

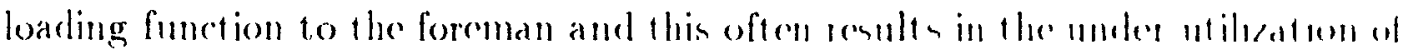

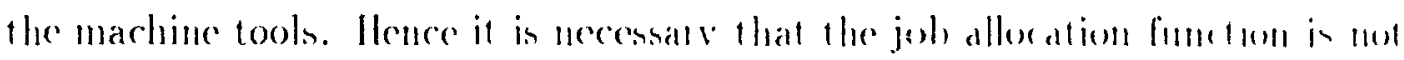
only optimized but also flexible chongh to be able fo integtate whth ofled and

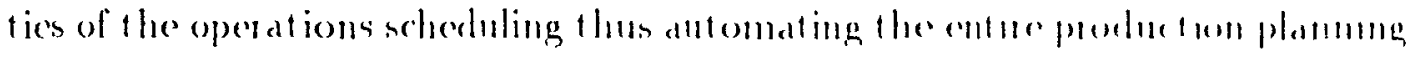
module. Such a link would enhance the sistem perfonmaner comstantme an mu portant step towards the integration of infommation flow in computed intregtated manufacturing (('IN).

\subsection{Thesis Outline}

The main objective of the thesis an to develope a new procedure to mplumere the

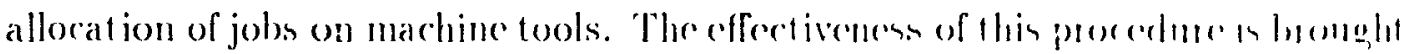

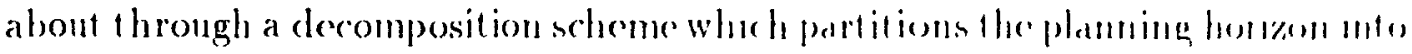
divisions. based the scheduled flow of jobs. The decompenstion seheme learls lo the development of an algorithm to solve job allocation poblenus and hinge to, light the possibility of integrating this with othes production planmmg fume tions. 


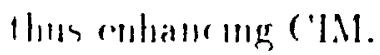

The impontance of the planning function in a manufacturing curviromment and the role of joh allocatom in the capacity decision functon are explained in chapter I The motivation for the study of these problems, how it aids in various decision making poocenses ane also discussed.

('hapter 2 provides a critical review of the wotk done on the problem of job allocatom problems The chapter concludes with an evaluation of the limitations impuserl by several of the existing solution procedures. It appears that because of the constraints and limitations involved in selecting the parameters, existing peocedures tend not to represent a realistic job shop environment. In this part of the Hesis an athempt is made to improve the situation.

('hrpter 3 discusses the need for partitioning the scheduling horizon and the punciples underlying a proposed scheme. The tinc decomposition scheme based on the setheduled flow of jobs is described in detail. The chapter also presents the dynamme optumzation principle which functions within cach partition to allocate jols on machine tools. The benefits of the partitioning scheme and dynamic optimizatom principle are described.

The algorithm based on the partition procedure and the dynamic optimization principle which were described in the previous sections, is outlined in Chapfor 1. The L.P. model for the job allocation problem is formulated and explained in detail. 'The functions of the aigorithm and its constituents, namely, the linear progrom and heuristios are presented. 


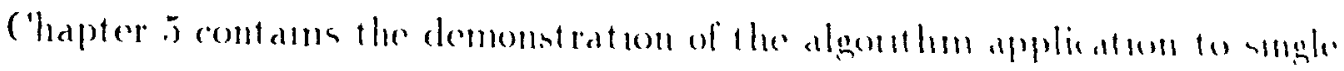

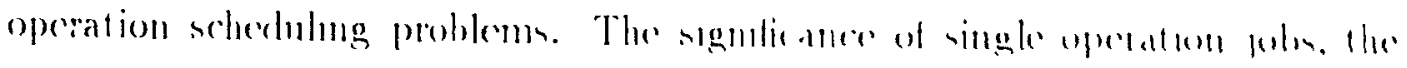

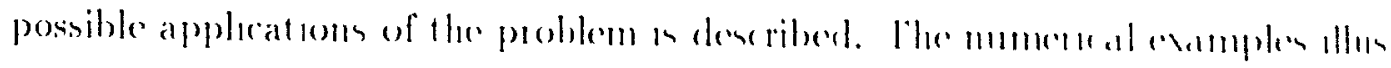

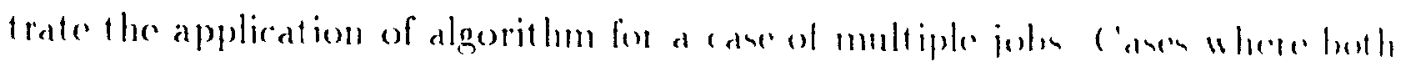
the starting and completion times of jole ale huenn and when ank the comple tion times are known, anc andlyzed. I sample control proglam aned to solw the

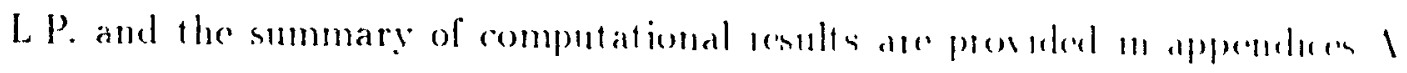

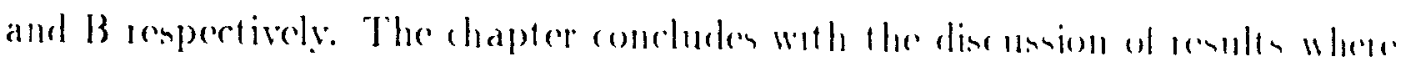

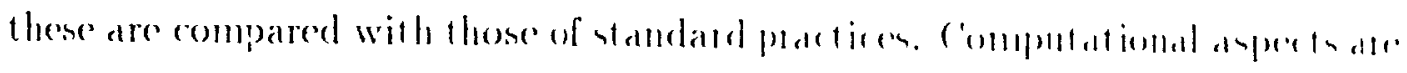
highlighted.

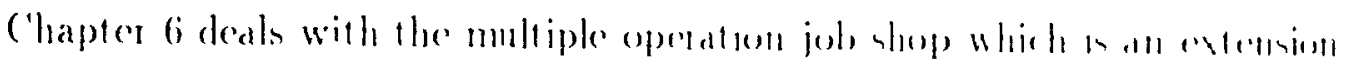

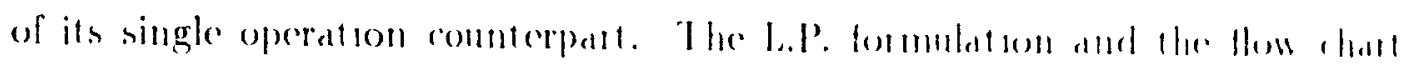

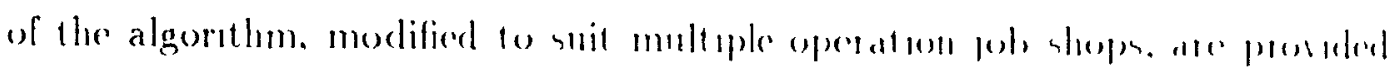

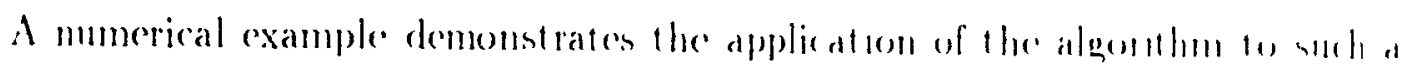
case. The results bring to light the benefits of the algenthim one the Shentent Processing Time (SP'T) rule.

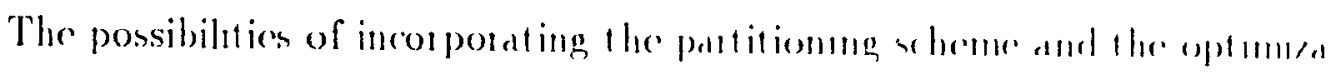

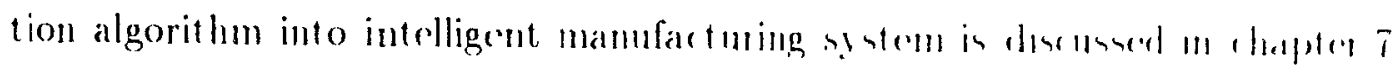
The various factors that should be comsdererl while denigmus smle an incerpen ration are also describerl.

Chapter 8 presents conclusions that may be drawn fiem the sturle wepented in the thesis, as well as recommendations for future rescedrh work. 


\title{
Chapter 2
}

\section{Job Allocation - State of the Art}

\section{Review}

\subsection{Literature Review of Studies on Job Allo- cation}

\begin{abstract}
The jub allocation problem falls into the general category of job-resource assignment. A vaticty of taxonomic procedures have been provided for dividing job allocation problems. Based on the processing complexity Graves [1] classifies the problems as:
\end{abstract}

I. One operation, onc processor

2. One operation, multi-processor

3. Multi operation job shop, tasks performed with identical precedence. 
4. Mult operation job shop, tasks performed without any precedence constraints.

In a multiple operation manufactuing envronment the job alloration problem has the most complex form: there are no restrictions on the processing steps for a task and alternative routings are allowed. This may be due to the completely: general nature of the multi-operation job shop category; however, for productuon lines which are limited by a bottleneck section, simpler rategories like smgle opcration problem arc important.

A standard approach to job-icsource aflocation problem is throngh the application of lincar programming. Typical for this approach are the work by Horn [2] and Powell [3]. The forme formulates the parallel machine tooks, single operation job shop scheduling problem as an assignment morled. The lineal programming formulation with minimum mean flow time criterion converts the model into an assignment problem. A similar approach is followed by Powell where a simple linear programming model to minimize the productive cost is formulated.

For a case of two identical machines Lawler and Mat tel [4] search for alloc ation to satisfy minimum late job requirement. In a three step algorithm the jols which are subjected to deadlines are schedules within the fixed time interval besides minimizing the number of late jobs. Since the procedure involves listing all possible schedules, it is a tedious approach and this becomes increasingly complex as the number of jobs increases. When $M$ identical machine tools are 
used to process $N$ jols, McNaghton [5] provides a solution procedure in which a loss function is defined for each job. The value of this function is proportional to the time between the deadline and the actual completion of the job: it is zero if the job is processed within the deadline. The jobs are assumed to be preemptive. However no examples were provided to demonstrate the solution procedure nor was the complexity of the procedure discussed.

Lincar programming deals with a static matrix of jobs and machines, which of conrse, represents a fundamental constraint, resulting not only in the departure from realistic situations, but also leading to increase in the size of problem. In order to tackle such large problems several techniques have been proposed to partition the planning horizon which will result in sub-problems of smaller size.

Perhaps the pioneering work in decomposing a general multi-stage linear programming problems was carried out by Dantzig [6]. The scheme consists of dividing the planning horizon into stages of equal time period and a s'stus vector defined at the beginning of each division such that this provides the only connertion between the stages. While the local optimum solutions are obtained by linear programming, global solutions are obtained by a master program using parametric programming. However, as Dantzig indicates, when the decisions are tied together by more than one variable this approach becomes tedious. An improvement in this procedure is suggested by Lasdon [7] in which the large number of columns of the L.P. model are handled by column generation through sub-problems instead of formulating a master program. Although it is clained 
that the number of iterations required to solve the problem is reduced by a factor of two in comparison with that of Dantzig, the computational complevity is quite significant in both these cases.

Although it is not confined to job assignment problems Wagner [8] addersses the issue of solving linear programming problems containing multiple but identical time periods. The variables are assigned unique subscripts for earh time periods and hence for $p$ periods there will be $n p$ terms in the objective function, where $n$ is the number of actual variables. Unfortunately the variables of all time periods are combined, and this approach will therefore not provide stange sub-problems representing each time period.

A partitioning scheme based on the arrival and completion times of jols is another approach to solve job allocation problems. Nasr and Elsaycd [9] suggest a partitioning scheme based on the finish times of jobs. All jobs are assumed to be non-preemptive and integer programming is used to solve the assignment problem. Integer programming solutions, however, are computationally intensive. To deal with the machine loading problem Jain et al. [10] divide the planning horizon into partitions of equal time durations, say months. In an integrated scheduling system the machine loading is carried out by an L.P. with an objective to maximize production and then employing heuristics to construct a feasible schedule for sequencing jobs at various work centers. The monthly subproblems are however, aggregated and the L.P. is solved for the whole planning horizon. 
Network graph teclinique is yet another method to solve the job distribution prol,lems. Dorsey $c t$ al. [11] addresses the problem of assigning the jobs to several irdentical marhines over a definite time horizon. The optimal solution is arrived at by an initial integer programming formulation with a minimum production, inventory and backorder costs criteria. Subsequently the model is converted into a network graph problem and solved. However, from the computational view point solving integer programming problems is tedious. Iwata et al. [12] treats the problem of assigning jobs to machines using network graph and an algorithmic procedure consisting of two dispatching rules, namely: earliest finishing time (EFT) and its extension which considers alternatc routings, EFTA. These proposed rules provide shorter makespan (makespan of a job is the time between its entry into the shop and its departure after processing) than other dispatching rules, the schedule is not however constrained by the due dates of jobs. As a result the setup times are added to the schedule after the assignment is carried out. When setup costs are considered in the schedule, mixed integer programming is used by Dilts [13] to solve the combined problem of lot sizing and job allocation.

\subsection{The work of M. Alaee at McGill University}

M. Alace [14], in order to formulate a procedure to solve job allocation problems, developed a method to partition the scheduling horizon based on the flow of 
jobs (i.e., input of jobs and their departure after processing). Arcording to this decomposition scheme the partitions are defined when a job enters the shop or when it leaves after processing. Thus within the time duration of the partition the product-mix on the shop floor remains constant.

The jobs within each partition are denoted by unicue subscripts. When the same job moves to the next partition, it assumes a different subscript. The joh, allocation is carricd out using an linear programming model with an objective to minimize makespan. The constraints for this L.P. are the time available on the machine tools during each partition and the total number of jobs processerl

Alternate routings are allowed i.e., a job can be processed on different machines. However, the machines are not identical and hence the processing times of the same job on different machines are not the same. The setup times are accounted for in the schedule by subtracting the setup time of cach job a priori from the available time on each machine. Thus irrespective of whether the job is loaded on the machine or not, setup times are deducted.

The solution procedure aggregates all the partitions: the L.P. contains the terms for all the partitions, both in the objective function and in thr constraints. This precludes full exploitation of the advantages of the partitioning procedure fuliy. The scheme presented in this thesis is based on this concept; in addition setup times are taken into account. An algorithm is developed subsequently to solve the sub-problems sequentially. 


\subsection{Concluding Remarks}

In the proposed allocation models, one or more of the following drawbacks are noticed:

1. In some of the works it is assumed that setup times are part of processing times. Ilowever, job shops are characterized by a variety of jobs which consume a considerable amount of setup time. It is difficult or sometimes inpossible to incorporate setup times/cost along with processing time/cost.

2. When several jobs are considered together, they are assumed to be available simultaneously and have a common completion time.

3. Alternate routings are not permitted and hence there is no chance of preemption. 'The jobs have to wait until the appropriate resource is free to load. However, in reality the resources in a job shop are flexible enough to handle a variety of jobs and hence there are alternate ways to process a job.

4. Most of the work done in the field of job shop scheduling, both for single and muitiple operations, assume that processors are identical.

5. In cases where quantity processed is the optimization criterion, obtaining integer solutions was found to be difficult. Some authors uses integer programming models for which the computational effort required is high, particularly when the size of the problem is large. 
6. Scheduling problems are solved for definite time horizon. So all the pardumeters within that horizon are assumed to be consiant.

7. When network graph technique is used in conjunction with henristics to solve scheduling problems, it was noticed that the computational offort increases for large scale problems. This is because the techuique involves listing of all possible schedules and sclecting the best anong them, for a given criterion.

Similar computational difficulty is experiened when dynamic programming appioach is used. 


\section{Chapter 3}

\section{Time Decomposition and}

\section{Dynamic Optimization}

\subsection{Necessity for Decomposition}

The problem that is often encountered in linear programming (L.P.) formulations of job allocation is that the jobs are assumed to be available at time zero and all jols have common completion times. Since job shops are characterized by parts that arrive at different times and have different due dates, this assumption may not hold good on most of the occasions. When L. P. formulation is attempted accounting for such job arrivals and departures, the number of variables increase, making the computational procedure difficult. The new partitioning scheme should address these drawbacks and also include the new jobs in the schedule as they arrive into the shop. 
Maintenance for marhine tools in a job shop can be scheduled at speritie time periods within the planning horizon. The machines will not be draldale for processing the jobs during maintenance periods and a job allor at ton shedule should accommodate this by taking into account the stating times and duration of scheduled maintenance. When the planning horizon is large, it is found to be diffeult to incorporate time periods during which the machines ane not avaliable.

For practical job allocation problems, computer storage may be an import.tut consideration. These problems may sometimes sequire mat rices of a size that lan even large, modern computers. In general, all these joh allocatwon publeme span a definite horizon and if such a problem could be divided into smalles probleme, then the computational effort can be reduced. However, while partitioning the scheduling horizon in this fashion, the sub-problems should be linked in surh a manner that there exists an effective coordination between theril.

It should be noted that the parameters such as proressing lime, sctup time and the associated cost, tend to decline as the learning curve progresse's. Another reason for this decline could be the technological advancement, of operations methodology. A linear programming formulation must however assume that these parameters are constant for a given time horizon. In the short run these may not affect the performance of the job allocation solution, as the time elements can be assumed to be fairly constant. However, if the time elements and the costs associated are variable or discontinuous over the full range of scheduling horizon, then the assumption of linearity will not provide a realistic solution. Hence, it. 
is often practical to segment an element of the time horizon and assign different time and cost values to each of the segments thereby approximating the behaviour of variables which are not constant. The immediate effect of such decomposition will be the increase in the size of the variable matrix and hence the computing time required to solve the problem.

Some progress has been made in developing methods for solving integer variable problems. While it can be stated that theoretically these methods will ultimately yield integer solutions, even small problems have been found to require great many itcrations and huge computer memories. Real life problems demanding integer solutions should be solved using approximations such that the solution procedure is economical.

\subsection{Time Decomposition Scheme}

The jobs (new materials and components) arrive in the shop for processing on a suitalule and available machine tool according to their respective process plan and schedule defined by the order releases and due dates. When considering the allocation of jobs on the machines, one should notice that their arrival and due dates are spread throughout the planning horizon. This rneans, the job mix on the shop floor is changing with time. As mentioned earlier, this situation complicates the L.P. formulation, which is a simple way to find the optimum solution for job-rcsource allocation problems. There are, however, time periods 
within the planning horizon, when the job mix on the shop floor cemains comstant Such periods occur when no new jobs arrive or a finished one leares the shop Moor. It is therefore possible to decompose the time of the plamming inomizon into constant job-mix stages. Any job arrival or departure meane a elange m the product mix on the floor, and therefore such an event marks the beginning on and of the stage. A job arrival to the shop floor on departure of a finished component. is an coent. A stage is defined as the time interval between two conts, dumng which the produrt mix is constant. A stage can also be fommen he romecontive arrivals or consecutive departures of any jobs. Thus the planning homzon an be divided into constant job-mix stages (CMS) based on the scheduled flow uf jubs. It is apparent that with $N$ jobs considered, there could he upto $2 N-1$ stagen. The concept of constant job-mix stages (CMS) formed by the time decompus, it ion method is illustrated in Fig 3.1.

The time and cost factors are assumed to be constant within a stage. Thin is valid as it provides a reasonable approximation for any existing vainbles whose values are changing with time, and also allows for a step change at an event. occurrence.

The division of the scheduling problem into stages (time periods when the job-mix is constant) has its advantages:

1. By partitioning the scheduling horizon based on the flow of jols, ach division has a constant mix of jobs. The dimension of the L.P. formulation is reduced because of this partitioning scheme. 
Job Arrivals

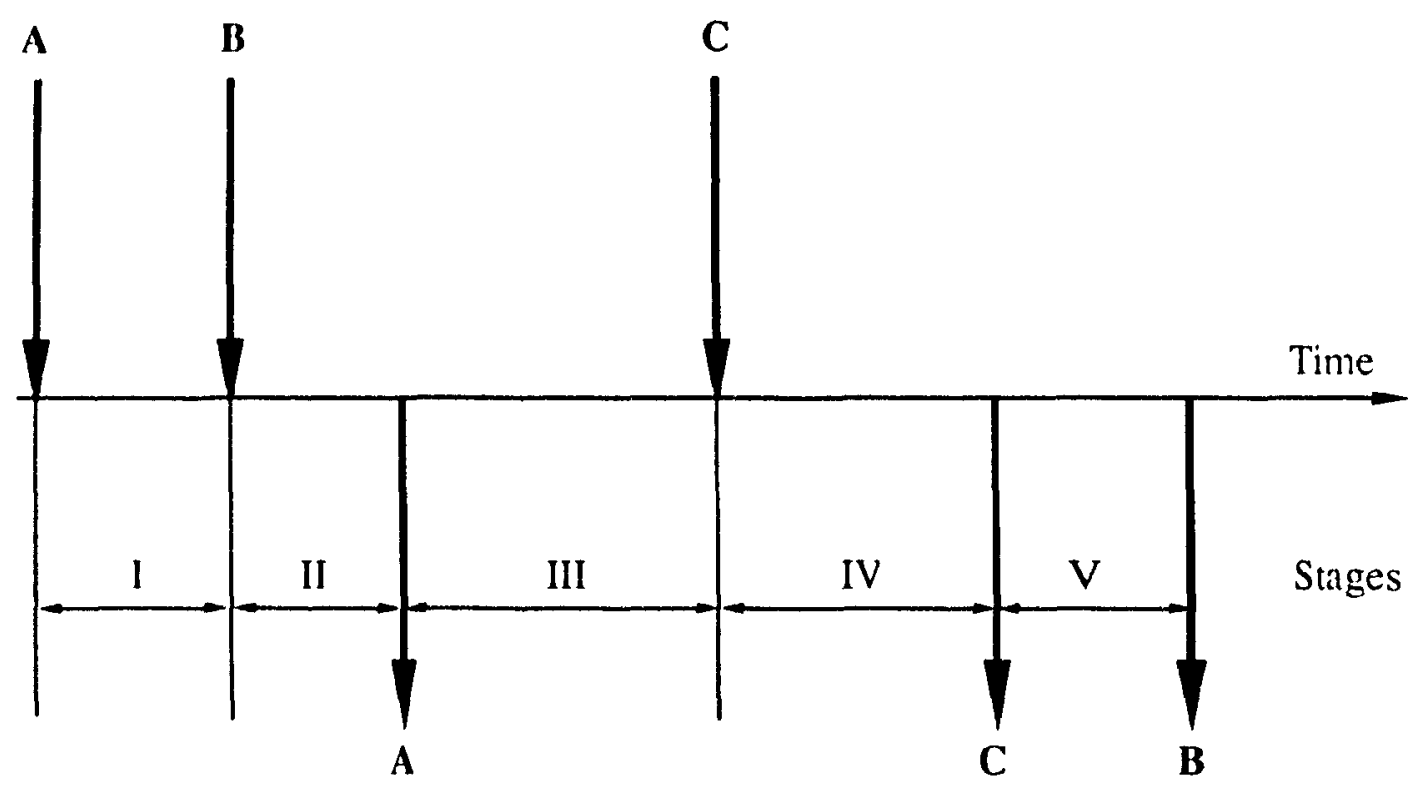

Due Dates

Fig 3.1 Schematic representation of constant job-mix stages 
2. Factors like machine aralability and alternate touting for fold an be incorporated accurately as these ase definced within cach pattitum.

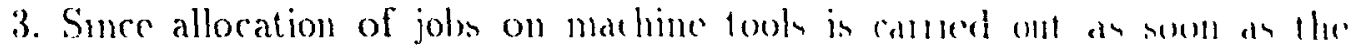

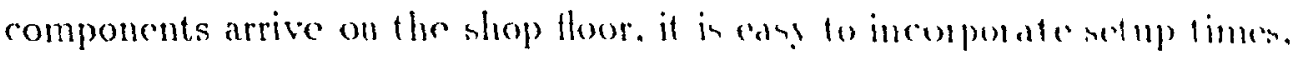
and this provides a realistic schedule.

4. Fom a comput at ional viewpoint, it is profitals to partition the e hedulung horizon and solve the sub-problems. since the comput atiental effort and the time required to solve an L.P. is proportional to the size of the problem

\subsection{Dynamic Optimization Principle}

The decomposition of the planning horizon into constant job-mix stages, operns the possibility of using L.P. to uptimize the job allocation on machine fools following the time-based schedule. The optimization can be carried ont within end stage, with the output of one stage forming the inpul for the subrequent, stage, in addition to the basic positive or negative input defining the beginning of this new stage. The job allocation solution of the L.P. indicates the cunntity of jolss to be processed on the available machine tools. This is redurted form the total demand quantity in order to obtain the remaining quantity to be processed during the subsequent stages and this forms the input for the next stage L.P. Considering that such a link between the stages continues thronghont the planning horizon, from stage to stage, the dynamic nature of both the problem and 
the optimization procerlure is apparent, and hence the procedure can indeed be ralled as dynamer optomization.

As will be seen in the following chapters, the optimization of job allocation within cach stage provides a more compact schedule. While this leads to compessing the schedule towards the due dates with backward decomposition, it movirles a schedule compressed towards the starting dates when forward decompessition is carried out. The former corresponds to the just-in-time philosophy with reduction of slack and work-in-process (WIP) inventory as its effects. The latter procerlure provides early shipment dates for orders and permits loading additional jobs on machine tools during the spare time. 


\section{Chapter 4}

\section{The Job Allocation Algorithm}

\subsection{Introduction}

Based on the time-partitioning scheme and dynamic optimmation principle, an algorithm is developed to optimize the allocation of jobs on marhine tools. The algorithm consists of two parts; the first part is the allocation problem which is formulated as a linear programming model and the second, a heuristic which will account for various functions, like: incorporation of setup times, obtaining integer solutions $e t c$. The job allocation procedure can be viewed as a recision making process, in which the quantity of cach job to be loarded on a particular machine tool is to be determined. Consequently, the decision making process is exercised over a discrete set of events in the scheduling horizon. In carh subproblem, the set of jobs (operations) available for allocation is ronsidered and the assignment for those jobs to machines is obtained with consideration given 
to local constraints like machine availability, capability and time available on machincs.

\subsection{L.P. Formulation}

The job allocation problem within each stage is formulated as a linear allocation model, with an objective to maximize the production rate of all the machines. The constraints for the L.P. are:

1. The production quantity should match the demand,

2. The time of processing of all the components on every machine cannot exceed the stage time period.

Some machines might not be available throughout the stage duration. When a machine tool is not capable of prosessing a particular job and/or when a machine is not available, the machine availability index $r_{\imath m}$ and processing capability index $s_{\jmath}$ gualantee that the objective function will contain only the valid nonzero terms. In all the equations found in tive L.P. formulation which follows, the subscript $i$ denoting the stage is unique; hence there will be $P$ stages representing the cntire problem. The L.P. formulation for a single stage job allocation problem is as follows: 
$\operatorname{Max} \quad\left\{\sum_{m=1}^{M}\left(\sum_{\jmath=A}^{N} r_{\imath m} s_{\jmath m} X_{\imath \jmath m}\right)\right\}$

subject to:

$$
\begin{array}{ll}
\sum_{m=1}^{M} r_{\imath m} s_{\jmath m} X_{\imath \jmath m} \leq Q, & j=A, B, \ldots, N \\
\sum_{\jmath=A}^{N} r_{\imath m} s_{\jmath m} R_{\jmath m} X_{\imath \jmath m} \leq T_{\imath m} & m=1,2, \ldots, M \\
X_{\imath \jmath m} \geq 0 & j=A, B, \ldots, N \\
& m=1,2, \ldots, M
\end{array}
$$

The first set of constraints state that the quantity of any job processed should not exceed the demand quantity. For components which are due by the cond of the stage the demand is met by equating the quantity processed to the remaining quantity i.e., in the demand constraint the $\leq$ operator is clanged to $=$. The second constraint set requires that the machine hours utilized in any stage should not exceed the capacity available on cach machine tool. The last one is a nonnegativity constraint for the quantity of any job processed in a stage.

The linear programming formulation of the allocation model is somewhat similar to the generalized transportation problem. The constraints are not equations but are inequalities which must be augmented by slack variables. Although the 
solution of a transportation model yields integer solutions directly, the allocation tableau is large and sparse. Storage and/or data accessing problems may arise.

The allocation model belongs to a special class of transportation problem called the multi-divisional problems which exhibit a special block angular structure (Hillier and Lieberman [16]). Each smaller block contains coefficients of the constraints for one sub-problem (one sub-problem represents one stage). Since the divisions operate with considerable autonomy, the problem is decomposable into separate problems, where each division is concerned with optimizing its own operation. The decomposition scheme makes use of this special structure in order to sulve the allocation problem. Moreover, the scheme also provides a schedule which is not bounded by time. Such an open ended schedule permits loading of jobs on a continuous basis, thus enabling realistic and short term scheduling.

\subsection{Setup Time Incorporation}

Setup times are incurred whenever a machine tool starts to process a new componcnt. If the lot is split among many machines, then all those machine tools undergo a setup. The job allocation problem is more difficult to solve when setup times are considered. For a given problem and ignoring the setup times, it is easy to test whether or not a feasible solution exists by comparing the cumulative demands to the cumulative capacity for all time periods and facilities. With setup times taken into account, the scheduling problem under consideration is found 
to be NP-complete i.e., cannot be solved in polynomial time (Garey et al. [15]).

Setup times are significant parameters in a job shop manufacturing covironment. This is due to the fact that a variety of components are processed in a job-shop. Setup times in job shops take more time than in other kinds of manufacturing environment. This is because job shops are flexible in processing a variety of complex jobs. Obviously, this will have an impact on meeting the due dates, especially in cases where the setup times are more than 500 times the processing times, which is often the case.

The setup times are incorporated after the initial allucation of jols on machine tools is carried out. This is because, in order to assign sotups, it is csiscutial to know which jobs are loaded on which machines. After assigning the approptide setup times on machines, the job allocation schedule is generated once again to obtain the final solution.

\subsection{Other Functions of the Algorithm}

The other functions of the algorithm, apart from setup time incorporation anc: providing integer solutions, updating demand quantity, reducing slack on machines, enforcing due dates for jobs and providing a link between the different. stages. Since the job allocation is solved using lincar programming, the solution contains real variables and this is unsuitable if only integers are arlmissible. In order to obtain integer values, the variables that enter the L.P. solution are rounded 
off to the nearest smaller integer. In other words, the variable is truncated. A cumulative effect of this might build slack on the machine tools. However, the CMS algor ithm also accounts for slack reduction by reassigning jobs on machines where slack exists. The necessary condition for this, of course is, that the required setup exists on these machines for a particular job.

Since the stage time durations are consi derably less than that of the planning horizon, the total demand quantity may not be processed within a stage. The CMS algorithm also updates the demand quantity of jobs at the end of every stage by deducting the quantity that has been processed during the stage. The romaining demand quantity to be processed in the subsequent stages, is the parameter which provides the link between the stages. The CMS algorithm also enforces the due dates for jobs which are due by the end of the following stage, by changing the $\leq$ operator in the quantity constraint to $=$.

\subsection{Algorithm Procedure}

Once the starting dates and due dates are known, the stages can be determined. The L.P. model of the job allocation problem for the first stage is then formed and solved. Based on the job allocation to machines in this stage, the setup times are deducted from the assigned time for each machine and the L.P. model is iterated. If there is no change in job allocation, then the quantities processed on carls machine are truncated to integers. Slack reduction on machines which 
have idle time and the due date enforcement is then carried out by reallocaling the jobs to machines. The demand quantity is then decreased by the quantity processed during the stage and constitutes the quantity to be processied in the subsequent stages. The quantity of all components processed duing the next stage is equated to the demand quantity, for all jobs which are due by the end this stage. These procedures are iterated until the job allocation in all the stinges is completed. The following algorithm provides the steps involved in the solution procedure.

Step 0: Formulate the Linear Programming (L.P.) model for the first stage.

Step 1: Solve the L.P. model.

Step 2: Based on the assignment of jobs, deduct setup times from the assigned times. If setup already exists on the machine, then do not deduct setup time.

if $X_{\imath \jmath m}>0$ and $X_{\imath-1, m}>0$, then $S_{\jmath m}^{\prime}=0$

for job $j$ having setup on machine $m$. Otherwise, $\left(T_{\imath m}\right)_{\text {new }}=\left(T_{\imath m}\right)_{\text {old }}-\sum_{j=A}^{N} S_{\text {jm }}$

Here, $\left(T_{i m}\right)_{\text {old }}$ refers to the available time on machine $m$ during stage $i$, before setup time incorporation.

Step 3: Solve the modified linear program. If the solution obtained indicates the same job allocation pattern as observed in step 1, the solution is chesen. 
Othorwise go to step $2^{1}$.

Step 4: The quantity processed during the stage is integer truncated.

Stey 5: If the current stage is the last stage for component $j$, and if the quantity procesized is less than the demand, then distribute job $j$ on machines which accept loads other than $j$.

If after rounding off, the following conditions exist:

1. $\sum_{m=1}^{M} X_{2 \jmath m} \leq Q$,

$2 . i$ is the last stage for component $j$.

3. $T_{\imath m}-\sum_{\jmath=A}^{N}\left(R_{\jmath m} X_{\imath \jmath m}\right) \leq R_{\jmath m}$

then,

$$
\begin{aligned}
& \left(T_{\imath m}\right)_{n c w}=\left(T_{\imath m}\right)_{o l d}-\left(\alpha \times R_{3 m}\right) \\
& \left(X_{\imath \jmath n}\right)_{n e w}=\left(X_{\imath \jmath m}\right)_{o l d}+\alpha
\end{aligned}
$$

for machines which accept load components other than $j$.

$$
\text { where } \alpha=\left(Q_{\jmath}-\sum_{m=1}^{M} X_{\imath \jmath m}\right) \text {. }
$$

\footnotetext{
${ }^{1}$ Note that the steps 2 and 3 in the algorithm will not loop Once the setup time is Incorporated, the available time on machines is reduced, thus fewer jobs are allocated on the marhines durng the next iteration The pattern of allocation often remains the same causing the algorithm to go to step 4. Loopmg can happen only when the stage duration is less than the setup tume. But when this happens, either the job processing is pestponed to subsequent stage or the enture stage duration is consumed for setup on the machne.
} 
Step 6: If there is slack on any machines, load job for which setup alreddy c vists on that machine; i.c., if the following conditions cxist:

$$
\begin{aligned}
& T_{\imath \jmath}-\sum_{\jmath=A}^{N} X_{\imath \jmath m} R_{\jmath m} \geq R_{\jmath m} \text { and } \\
& \sum_{m=1}^{M} X_{\imath \jmath m} \leq Q_{A}
\end{aligned}
$$

then,

$$
\begin{aligned}
& \left(X_{\imath \jmath m_{n e w}}=\left(X_{\imath \jmath m}\right)_{o l d}+a\right. \\
& \text { provided, } \quad\left(X_{\imath \jmath m}\right)_{n e w} \times R_{\jmath m} \leq T_{\imath m}, \\
& \text { where } \quad 0<a<Q_{A}-\sum_{m=1}^{M} X_{\imath \jmath m}
\end{aligned}
$$

Step 7: If this is the last stage, then terminate, else proceed to step 8.

Step 8: For all $X_{23 m}$ in the solution, subtract the quantity processed from the demand quantity to obtain the remaining quantity to be processed in the next stage ${ }^{2}$.

Step 9: For any component which has rlue date during the encl of next stage the $\leq$ operator in the time availability constraint is changerl $10=$.

Step 10: Form the L.P. model based on step 8 and step 9. Go to step 1.

\footnotetext{
${ }^{2}$ The steps 9 and 10 belong to the next stage.
} 


\section{Chapter 5}

\section{Application of Algorithm to}

\section{Single Operation Job Shops}

\subsection{Analysis of the Problem}

The single operation, multiple job scheduling problem is an important generalization of a job shop. The task or operation requires one processing step which may be performed on any of a number of similar machine tools. In a production line, the different operations performed on a particular job need not consume the same amount of time. A slower operation in an unbalanced line constitutes a bottlenerk. The output of a bottleneck (slowest) operation decides the output of the entire production line. In such situations, it may be sufficient to consider only the bottleneck operation and analyze it If the cause for bottleneck can be attributed to ineficient loading patterns, iob allocation can be optimized on 
this operation using the CMS algorithm. Besides increasing the throughput, this exposes other existing problems in the production line. 'This aids in solving the problems, thus enhancing the throughput and efficiency of the overall shop.

The theoretical insight obtained by analyzing the single operation job allocation problem is helpful in tackling more complex problems. These serve ds building blocks for understanding the decision processes involved in multiple operation job assignment problems. Individual optimization of single operation jobs may provide a global sub-optimal solution.

\subsection{Problem Definition}

The classic multi-item, single opcration, malti-machine tool joh allocation problem can be stated as follows.

1. There are $N$ items to be scheduled.

2. There are $M$ machines which are not identical. These machines may of may not be capable of processing all the $N$ jobs.

3. Unit processing time $R_{y m}$ is incurred when the machine $m(m=1,2,3, \ldots$, M) processes job $j(j=A, B, C, \ldots, N)$.

4. Setup time $S_{\jmath m}$ is incurred whenever a machine $m$ starts processing a new job $j$. Setup times are unique for a particular job on a pastirular marlume.

5. Due dates are specified for each type of jol. 
6. The demand quantities $Q,(j=A, B, C, \ldots, N)$ for all jobs are known.

7. All machines may or may not be available throughout the planning horizon.

\subsection{Scheduling from the Starting Times}

In situations where job arrival times are known, scheduling jobs from the start dates is prudent as it determines the actual completion date of the operations. The jolss are processed as soon as they arrive on the shop floor. This provides a loading pattern in which the schedule is compacted towards the start dates. Early shipment dates for all the orders is an obvious result of such schedule.

\subsubsection{Numerical Example}

A case of four jobs to be processed on four machines is considered to demonstrate the application of thr algorithm described in Chapter 4. Each job undergoes only onc operation and there are alternate machines to perform each operation. All jols are to be processed in specific quantity and their arrival and duc dates are known in advance. The processing time of different jobs on machines is provided in Table 5.1. The demand quantity of jobs and their due dates are given in Table 5.2 while the availability of different machine tools during the planning horizon is shown in Table 5.3. The constant job-mix stages for this problem is illustrated in Fig 5.1. The problem is to allocate jobs on machine tools in such a way that the output is maximized. 
Table 5.1: Processing times of jobs.

\begin{tabular}{||c|c|c|c|c||}
\hline \multirow{2}{*}{ Machine } & \multicolumn{3}{|c|}{ Proc. tume $(\mathrm{mm})$} \\
\cline { 2 - 5 }$m$ & $\mathrm{~A}$ & $\mathrm{~B}$ & $\mathrm{C}$ & $\mathrm{D}$ \\
\hline 1 & 3 & - & 2 & 6 \\
\hline 2 & - & 8 & 3 & 7 \\
\hline 3 & 5 & 10 & - & 12 \\
\hline 4 & 10 & - & 4 & 9 \\
\hline
\end{tabular}

The algorithm provided in the previous chapter is applicable for a gemeral case. Moreover in the current example the setup tines ane not considened. Hence, some of the steps may not be applicable for the case under comidenation and hence are omitted. 
Tablo 5.2: Demand quantities, arrival and due dates.

\begin{tabular}{||c|c|c|c||}
\hline$J o b$ & $\begin{array}{c}\text { Quantıty } \\
Q_{A}\end{array}$ & $\begin{array}{c}\text { Arrival } \\
(\mathrm{mm})\end{array}$ & $\begin{array}{c}\text { Due date } \\
(\mathrm{min})\end{array}$ \\
\hline $\mathrm{A}$ & 420 & 0 & 3600 \\
\hline B & 240 & 900 & 2500 \\
\hline C & 1800 & 1200 & 4400 \\
\hline D & 400 & 3000 & 6000 \\
\hline
\end{tabular}

Table 5.3: Availability of machme tools.

\begin{tabular}{||c|c|c||}
\hline $\begin{array}{c}\text { Machine } \\
m\end{array}$ & $\begin{array}{c}\text { Avalable } \\
(\mathrm{min})\end{array}$ & $\begin{array}{c}\text { Not avalable } \\
(\mathrm{m} \imath \mathrm{n})\end{array}$ \\
\hline 1 & $0-6000$ & 0 \\
\hline 2 & $0-6000$ & 0 \\
\hline 3 & $0-2000$ & $2000-3000$ \\
\hline 4 & $3000-6000$ & \\
\hline
\end{tabular}




\section{Stage 1}

Step 0: First stage L.P. is formulated as follows:

$\operatorname{Max}\left(X_{A 11}+X_{A 13}\right)$

Subject to:

$X_{A 11}+X_{A 13} \leq 420$

$3 X_{A 11} \leq 900$

$5 X_{A 13} \leq 900$

Step 1: Solution for this L.P. is $\left\{X_{111}=300, X_{A 13}=120\right\}$

Step 10: The next stage L.P. is formulated as follows:

$$
\begin{aligned}
& \text { Max } \quad\left(X_{B 22}+X_{B 23}\right) \\
& \text { Subject to: } \\
& X_{B 22}+X_{B 23} \leq 240 \\
& 8 X_{B 22} \leq 300 \\
& 10 X_{B 23} \leq 300
\end{aligned}
$$

\section{Stage 2}

Step 1: Solution $\left\{X_{B 22}=37.5, X_{B 23}=30\right\}$

Step 4: $\left\{X_{B 22}=37, X_{B 23}=30\right\}$ 
Sirp s: $Q_{B}-\left\{X_{B 22}+X_{B 23}\right\} \Rightarrow 240-67=173$

Sicp 10: The next stage L.P. is formulated as follows:

$$
\begin{aligned}
& \text { Max } \quad\left(X_{B 32}+X_{B 33}+X_{C 31}+X_{C 32}+X_{C 34}\right) \\
& \text { Sulject to: } \\
& X_{B 32}+X_{B 33}=173 \\
& X_{C 31}+X_{C 32}+X_{C 34} \leq 1800 \\
& 2 X_{C 31} \leq 1300 \\
& 8 X_{B 32}+3 X_{C 32} \leq 1300 \\
& 10 X_{B 33} \leq 1300 \\
& 4 X_{C 34} \leq 1300
\end{aligned}
$$

\section{$\underline{\text { Stage } 3}$}

S'rp 1: Solution $\left\{X_{B 32}=93, X_{B 33}=80\right.$,

$$
\left.X_{C 31}=650, X_{C 32}=185.33, X_{C 34}=25\right\}
$$

Step 4: $\left\{X_{B 32}=93, X_{B 33}=80\right.$,

$$
\left.X_{C 31}=650, X_{C 32}=185, X_{C 34}=25\right\}
$$

Step $8: Q_{C}-\left\{X_{C 31}+X_{C 32}+X_{C 34}\right\} \Rightarrow 1800-860=940$

Step 10: The next stage L.P. is formulated as follows: 
$\operatorname{Max} \quad\left(X_{C 41}+X_{C 42}+X_{C 41}\right)$

Subject to:

$X_{C 41}+X_{C 42}+X_{C 44} \leq 910$

$2 X_{C 41} \leq 500$

$3 X_{C 42} \leq 500$

$4 X_{C 44} \leq 500$

The problem is solved for the remaining stages in the simila fashien.

\subsubsection{Results and Discussion}

The linear programming problem for all the stages was solved using IBMA MIPSiX software on a IBM 3090 mainframe. The final results obtained by the application of CMS algorithm are provided in Table 5.4 and this shows the assigmment of various johs during each stage. As the problem conld be solved with all stages aggregated together using a linear programming formulation, it is combitered an a basis for result comparison. The objective function and the time availability constraints of such an aggregated formulation are obtained hy combining thuse of the stages. Table 5.5 and 5.6, and Figure 5.1, show a comparison between the CMS algorithm and the aggregated approach.

As can be seen from Fig 5.1, the job distribution on machine took is compressed towards the starting times when CMS algorithm is used, whercas in aggregated approach the jobs are processed in rather a discontinuons manner. 
The derrease in makespan of johs, as in Table 5.5., is the effect of such schedule compression: a maximum of $68 \%$ reduction in makespan is indicated for indivirlual jobs. The obvious result of this is shorter completion time of jobs (Table $5.5)$, due to the fact that the jobs are loaded on any available machine tool as soon as they arrive on the shop floor.

The important benefit of using the decomposition scheme and optimization is an increase in utilization of the machine tools. Machine tool utilization is defined as the ratio of the time when the machine is busy to the time between the entry of first job and completion of the last job on the machine. Table 5.6 shows a comparison of utilization between CMS algorithm and aggregated approach. The maximum output objective of the linear program ensures that within each stage the jolss are loaded on the available machine tools and no machine is left idle if any joh which the machine is capable of processing, is present on the shop floor. Thus the machine tool utilization is maximized in every partition, providing a cumulative effect of overall maximization of machine tool utilization.

Since the schedule is compacted towards the starting dates and makespan of jobs is reduced, free time is made available on machines and this can be used to process other jobs. This also helps to provide early shipment of orders.

From a computation time viewpoint, the partitioning of the time horizon and optimizing the sub-problems, proves to be profitable. For a linear program the computational time roughly equals the third power of the number of functional constraints (Hillier and Lieberman [16]). When a problem is decomposed, the 
sub-problems contain far fewer constraints than the latge problem. Thus the computational time of all the sub-problems added is substantially reduced in comparison with that of the large problem. For a general $N$ joh $M$ machine problem, when all the $P$ stages are aggregated the number of constraints present will be $\left(N+\sum_{t=1}^{P} M_{t}\right)$, while that of single slage is $M_{t}+N_{t}$. Fion $P$ strges. the number of constraints present will be $\sum_{t=1}^{p}\left(M_{t}+N_{\imath}\right)$. Hence, Her savings in computational time when the problem is solved using ("NS algorithm is

$$
R_{T}=\frac{\left(N+\sum_{t=1}^{P} M_{t}\right)^{3}}{\sum_{t=1}^{P^{\prime}}\left(M_{t}+N_{t}\right)^{3}}
$$

For the example case the number of constraints present in the aggegaled l..P in 28 while that of the 6 stages are $\{3,3,6,4,6,5\}$. The savings in compulational time will be:

$$
R_{T}=\frac{28^{3}}{3^{3}+3^{3}+6^{3}+4^{3}+6^{3}+5^{3}} \Rightarrow 32.5
$$

Hence the algorithm approach is 32 times less time consuming than the aggregated approach. This shows the implication of partitioning on the computational time effort required, which will be even more pronounced when problems of larger size are considered.

\subsection{Scheduling from the Completion Times}

Scheduling from completion times presents two important advantuges:

1. It provides a schedule which is compacted towards the due deters. 
Table 5.4: Final allocation of Jobs

\begin{tabular}{||c|c|c|c|c|c|c||}
\hline Marhine & Stage 1 & Stage 2 & Stage 3 & Stage 4 & Stagc 5 & Stagc 6 \\
\hline 1 & $X_{A 11}=300$ & $\dagger$ & $X_{C 31}=650$ & $X_{C 41}=250$ & $X_{C 51}=300$ & $X_{D 61}=133$ \\
\hline 2 & $\dagger$ & $X_{B 22}=37$ & $X_{B 32}=93$ & $X_{C 42}=166$ & $X_{C 52}=99$ & $X_{D 62}=108$ \\
& & & $X_{C 32}=185$ & & $X_{D 52}=43$ & \\
\hline 3 & $X_{A 13}=120$ & $X_{B 23}=30$ & $X_{B 33}=80$ & $\ddagger$ & $X_{D 53}=50$ & \\
\hline 4 & $\ddagger$ & $\ddagger$ & $X_{C 34}=25$ & $X_{C 44}=125$ & $X_{D 54}=66$ & \\
\hline
\end{tabular}

$\dagger=$ Machme not capable of processing a particular job

$$
\ddagger=\text { Machme not available }
$$

Table 5.5: Comparison of completion time and makespan

\begin{tabular}{||c|c|c||c|c|c||}
\hline \multirow{2}{*}{ Jobs } & \multicolumn{2}{|c||}{ Compl. time (min) } & \multicolumn{3}{|c||}{ Makespan (min) } \\
\cline { 2 - 6 } & Stagc & Aggr. & Stage & Aggr. & reduction \% \\
\hline A & 900 & 2860 & 900 & 2860 & 68.5 \\
\hline B & 2000 & 2500 & 1100 & 1600 & 31.3 \\
\hline C & 3600 & 4400 & 2400 & 3200 & 25.0 \\
\hline D & 4100 & 6000 & 1400 & 3000 & 53.3 \\
\hline
\end{tabular}




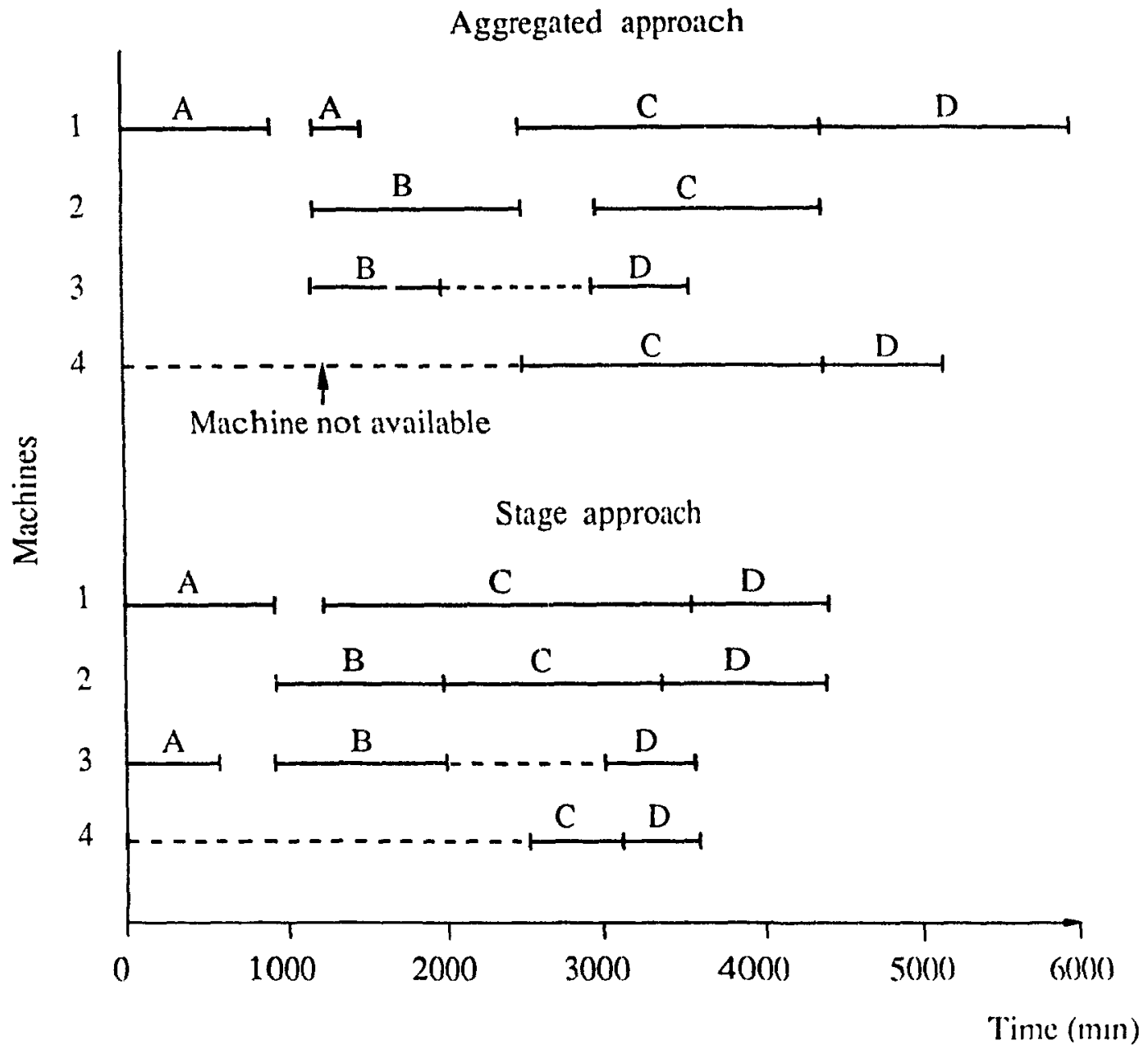

Fig 5.1. Allocation of jobs on machine tools based on Aggregated approach and Stage approach 
Table 5.6: Comparison of utilisation

\begin{tabular}{||c|c|c|c||}
\hline \multirow{2}{*}{$\begin{array}{c}\text { Machinc.s } \\
m\end{array}$} & \multicolumn{2}{|c|}{ Utilisation \% } & \multirow{2}{*}{$\begin{array}{c}\text { Increase } \\
\text { Stage }\end{array}$} \\
\cline { 2 - 4 } Aggr. & Stage/Aggr. \\
\hline 1 & 93.1 & 77.5 & 1.2 \\
\hline 2 & 78.3 & 44.9 & 1.7 \\
\hline 3 & 88.5 & 53.1 & 1.6 \\
\hline 4 & 99.5 & 96.2 & 1.0 \\
\hline
\end{tabular}

2. Late stant dates is obtained for all jobs. This corresponds to just-in-time (JIT) philosophy:

As a result of JIT schedule work-in-process (WIP) inventory is reduced and Clearly this leads to a lot of saving especially for components which have high raw material value and for those components for which the value increases rapidly as the operations progress. Since the schedule is compacted, the production process can be organized such that inventories are strategically placed throughout the process. Then, by carefully reducing these inventories certain production problems are exposed. Solving these reduces costs and lead times and improves quality: The following example demonstrates how the partitioning scheme can be applied to cases where the starting dates are unknown. Comparison of results with that obtained by applying SPT rule is also provided. 


\subsubsection{Numerical Example}

Let us consider a problem of allocating 8 jobs on 5 machines. The processing times and the setup times of various jobs on different marhines are proviturl in the Table 5.7 and Table 5.8. The 'f' symbers in these tables indieate the' machine is not capable of processing the particular jol. For the problem at haud. the machines are assumed to be aralable throughout the scheduling horizon $11 .$. there are no downtimes. Talse 5.9 presents the demand quantities of diffencun jobs and their stipulated due dates.

In this example, it is assumed that only the due dates are known, while the starting times are not known initially. Hence the following barkward stherfulung procedure is adopted to determine them. Starting from the due date of the last component, jobs are assigned to machines using SP' tuke withont premption If two or more jobs compete for the same machine, the job which has the lentst. processing time is assigned to the machine. The remaining job a: int ibment to other available machines (based on SPT rule). When this procendure in cantind out for all the jobs, it generates a loading pattern with the late statl daten which serve as a reference to define the stages (Fig 5.4). The SP'T rule was selected because, this rule ensures high machine utilization and performs better than other priority rules in situations where jobs arrive in the shop at different times. This provides the least favourable conditions to which the results of the ('MS methorl are compared. 
Table 5.7: Processing times of jobs.

\begin{tabular}{||c|c|c|c|c|c|c|c|c||}
\hline \multirow{2}{*}{ Machine } & \multicolumn{7}{|c||}{ Procssing tıme (min) } \\
\cline { 2 - 9 } & $\mathrm{A}$ & $\mathrm{B}$ & $\mathrm{C}$ & $\mathrm{D}$ & $\mathrm{E}$ & $\mathrm{F}$ & $\mathrm{G}$ & II \\
\hline 1 & 2.0 & $\dagger$ & 3.5 & 4.0 & 2.0 & 3.0 & $\dagger$ & 3.5 \\
\hline 2 & 1.7 & 3.0 & $\dagger$ & $\dagger$ & $\dagger$ & 2.8 & 2.7 & 3.2 \\
\hline 3 & $\dagger$ & 3.5 & 2.7 & 4.3 & 2.4 & $\dagger$ & 2.5 & $\dagger$ \\
\hline 4 & 2.1 & 3.8 & 3.9 & 3.7 & $\dagger$ & 3.1 & 3.0 & $\dagger$ \\
\hline 5 & 1.5 & $\dagger$ & 3.0 & 4.2 & 2.3 & 3.5 & $\dagger$ & 3.1 \\
\hline
\end{tabular}

$\dagger=$ Machine not capable of processing the job

Table 5.8: Setup times of jobs on machines.

\begin{tabular}{||c|c|c|c|c|c|c|c|c||}
\hline \multirow{2}{*}{ Machine } & \multicolumn{7}{|c||}{ Setup time (min) } \\
\cline { 2 - 9 } & A & B & C & D & E & F & G & H \\
\hline 1 & 200 & $\dagger$ & 195 & 145 & 150 & 155 & $\dagger$ & 110 \\
\hline 2 & 235 & 2.10 & $\dagger$ & $\dagger$ & $\dagger$ & 160 & 175 & 140 \\
\hline 3 & $\dagger$ & 230 & 210 & 100 & 120 & $\dagger$ & 200 & $\dagger$ \\
\hline 1 & 200 & 220 & 190 & 180 & $\dagger$ & 150 & 160 & $\dagger$ \\
\hline 5 & 210 & $\dagger$ & 200 & 100 & 145 & 120 & $\dagger$ & 145 \\
\hline
\end{tabular}

$\dagger=$ Machme not capable of processing the job 
Table 5.9: Demand quantities and due daten.

\begin{tabular}{||r|r|r||}
\hline Job & Qunntity & Dur date $(\mathrm{mm})$ \\
\hline A & 1500 & 5000 \\
\hline B & 2000 & 7000 \\
\hline C & 1500 & 9000 \\
\hline D & 1000 & 9000 \\
\hline E & 5000 & 12000 \\
\hline F & 3000 & 15000 \\
\hline G & 3000 & 16000 \\
\hline H & 4000 & 17000 \\
\hline
\end{tabular}




\subsubsection{Results and Discussion}

Re'sults of the example are given in Figures 5.2 to 5.4 and Tables 5.10 to 5.13 . As can be seen fiom the figures, the method of dynamic optimization (CMS) using decomposition into constant job-mix stages generates a considerably more compressed schedule than normal backward scheduling based on SPT rule. The late stat ts are puller towards the due dates, corresponding to the just-in-time philosoplyy.

The pattern of job allocation on machines using the CMS method is shown in Figure 5.2. It provides a good illustration of the effect of pull logistics. The corresponding numerical data for the late starts are given in relation to the due dates, in Table 5.10.

The inherent feature of job allocation which is visible in Figure 5.3 is the distribution of setup times. While in the common practice of assigning a job to machinc with SPT, only one setup is needed for the full processing time of this joh (Figure 5.3 a), this is not the case with the CMS method. In the new method setups are assigned to various machines according to the optimized solution, in which setup times are taken into account. In this procedure the setups may be repeated on the same machine in various stages if another job has to be processed in the moantime to meet the due date. Improvement in sequencing is however, possible.

The compressed schedule, in which the distributed setups form an integral part, permits an increase machine tool utilization (Table 5.11) and provides 
considerable frec capacity concentrated carly in the schedule; the fiece apuents can be used to process additional jobs. The total frec apacity of the shop is increased by nearly $50 \%$ (Tahle 5.12 ). The utulization of machines in a alenlated as the ratio of time a machine is busy (including the setul) times) to the fot.d time-span in the shop between the stat of the first job to the lant dire date and

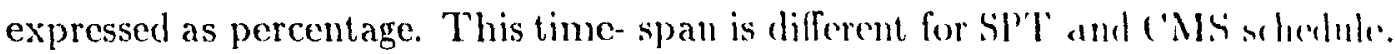
As can be seen from Figure 5.3 and Table 5.11 , machine \# 2 is the busiest one

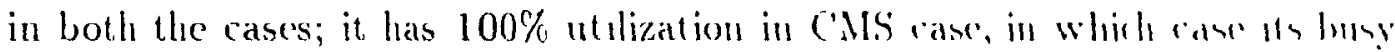
time is equal to the total shop time-span. The ntilzad ion of remaining mand himes would have been higher than indicated $78 \%$ to $86.3 \% \%$, if not for the ont of tange earlies start of machine \# 2. which defines the denominator of the mtolisalion ratio. Table 5.11 indicates that the increase of utiluzation in the rane of ('Mls over SPT, while vay ying from machine to machine, waches 1.87 (1.e . $87 \%$ hugher) for machine \# 4. The increase of the machine utilization reflects the compunsisun of the schedule.

To verify the increase of production rate of the shop due to the ('MS' a ti mization of job allocation, production output (total mumber of pirecen puendured on all machines) is divided by the total shop time-span, as in the ase of uthlyation. Thus, for SPT: $\quad 21000 /(17000-200)=1.25 \mathrm{pcs} / \mathrm{min}=7.5 \mathrm{pr} \cdot \mathrm{s} / \mathrm{hr}$ for CMS: $\quad 21000 /(17000-2120)=1.41 \mathrm{pcs} / \mathrm{mm}=8.1 .7 \mathrm{pm} / \mathrm{s} / \mathrm{m}$ This constitutes $12.9 \%$ production rate increase with C:MS. However, Hor puesent 
example puts the CMS method at disadvantage due to the fact that machine \#2 precerdes the starts of all other machines by $4000-2120=1880 \mathrm{~m} n$. If the shop time-span was counted from the start of these all other machines at $4000 \mathrm{mmn}$ then, with the production output reduced by the amount produced by machine \# 2 during these $1880 \mathrm{~min}$, then the production rate would be:

for modified CMS: $(21000-636) /(17000-4000)=1.57 \mathrm{pcs} / \mathrm{min}=94 \mathrm{pcs} / \mathrm{hr}$

1.r., $25 \%$ produrtion rate increase.

The increase in production rate as well as the compression of the schedule due to (MS optimization is reflected in the reduction of makespan. As Figure 5.4 and Trble 5.13 show, individual jobs experience up to $71 \%$ makespan reduction in comparison with SPT case.

This example permits assessment of the advantages of job allocation using constant job-mix stages. Shorter lead times, lower inventory (WIP) and additional capacity have been recognized by Goldratt [17] as having a major effect on the throughput. Of course, the new capacity has an effect only when it is utilized.

An important bencfit of the decomposition of the problem is the reduction of computational time. The expression derived in section 5.3 .2 can be applied here also. For the example studied, the non-decomposed problem contains 5i constraints, while the number of constraints for each stage sub-problem is $\{4,7,8,8,7,9,7,4,7, T, 1\}$. Hence the savings in computational time will be

$$
K_{T}=\frac{58^{3}}{1^{3}+7^{3}+8^{3}+8^{3}+7^{3}+9^{3}+7^{3}+4^{3}+7^{3}+7^{3}+4^{3}} \Rightarrow 53.31
$$


Table 5.10: Comparison of late start times.

\begin{tabular}{|c|r|r|r||}
\hline \multirow{2}{*}{ Jobs } & Late slart tumes $(\mathrm{min})$ & Due Dales \\
\cline { 2 - 4 } & $S P T$ & $C M S$ & $(\mathrm{~mm})$ \\
\hline A & 1680 & 4040 & 5000 \\
\hline B & 200 & 2120 & 7000 \\
\hline C & 4040 & 6410 & 9000 \\
\hline D & 5120 & 5120 & 9000 \\
\hline E & 1850 & 7990 & 12000 \\
\hline F & 6440 & 9000 & 15000 \\
\hline G & 8300 & 12000 & 16000 \\
\hline H & 4455 & 6600 & 17000 \\
\hline
\end{tabular}

Thus it will take 53 times less computational time to solve the problem using CMS algorithm than when all stages are aggiegated together. 
Table 5.11: Compatison of utilisation.

\begin{tabular}{|c|r|r|r||}
\hline \multirow{2}{*}{ Marhunes } & \multicolumn{2}{|c|}{ Utzlization \% } & Increase factor \\
\cline { 2 - 4 } & SPT & CMS & CMS/SPT \\
\hline 1 & 60.4 & 86.3 & 1.43 \\
\hline 2 & 88.1 & 98.6 & 1.14 \\
\hline 3 & 71.2 & 80.4 & 1.13 \\
\hline 4 & 42.9 & 80.4 & 1.87 \\
\hline 5 & 74.7 & 78.0 & 1.04 \\
\hline
\end{tabular}

Table 5.12: Comparison of free capacity.

\begin{tabular}{||c|r|r|r||}
\hline \multirow{2}{*}{ Marhuncs } & \multicolumn{2}{|r|}{ Frec capacity (min) } & Increase factor \\
\cline { 2 - 4 } & SPT & CMS & CMS/SPT \\
\hline 1 & 1850 & 4000 & 2.16 \\
\hline 2 & 200 & 2120 & 10.60 \\
\hline 3 & 1010 & 4000 & 0.99 \\
\hline 4 & 1680 & 4000 & 2.38 \\
\hline 5 & 4.455 & 4000 & 0.90 \\
\hline Total & 12225 & 18120 & 1.48 \\
\hline
\end{tabular}


Table 5.13: ('omparison of makespan

\begin{tabular}{|c|c|c|c|}
\hline \multirow[t]{2}{*}{ Jobs } & \multicolumn{2}{|c|}{ Makespan (min) } & \multirow{2}{*}{$\begin{array}{c}\text { Heduchom } \\
1 / 1\end{array}$} \\
\hline & $S P T$ & ( $M M S$ & \\
\hline$\Lambda$ & 33320 & 960 & 71 \\
\hline B & 6800 & .1880 & 28 \\
\hline$C^{\prime}$ & 1260 & 1860 & 56 \\
\hline $\mathrm{D}$ & 3880 & 3880 & 0 \\
\hline$E$ & 10150 & 4010 & 60 \\
\hline$F$ & 8560 & 6000 & 30 \\
\hline $\mathrm{G}$ & 7700 & 1000 & 18 \\
\hline II & 12545 & $10 \cdot 100$ & 17 \\
\hline
\end{tabular}



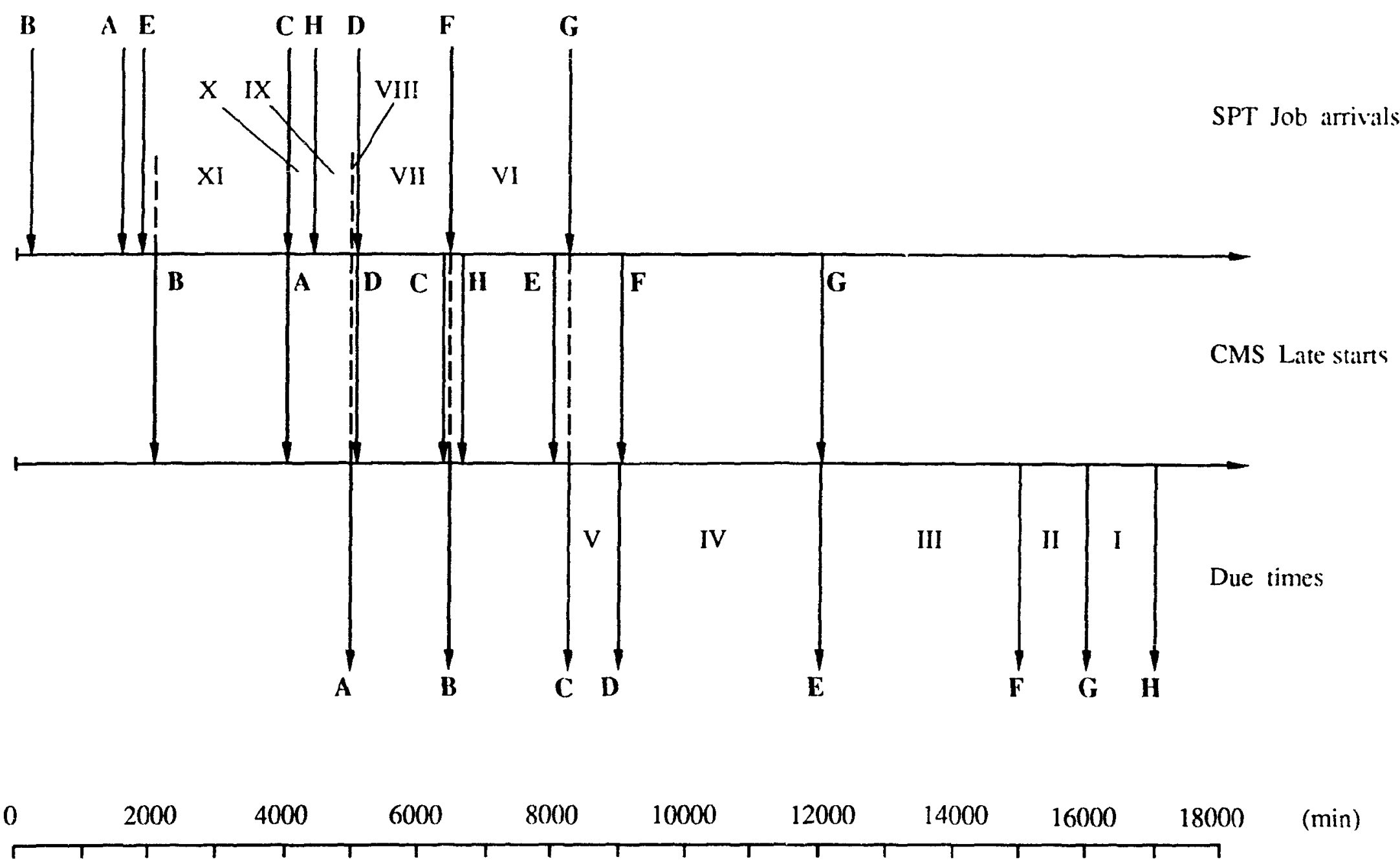

Fig 5.2 Job arrivals (SPT), late starts (CMS) due times and stages 


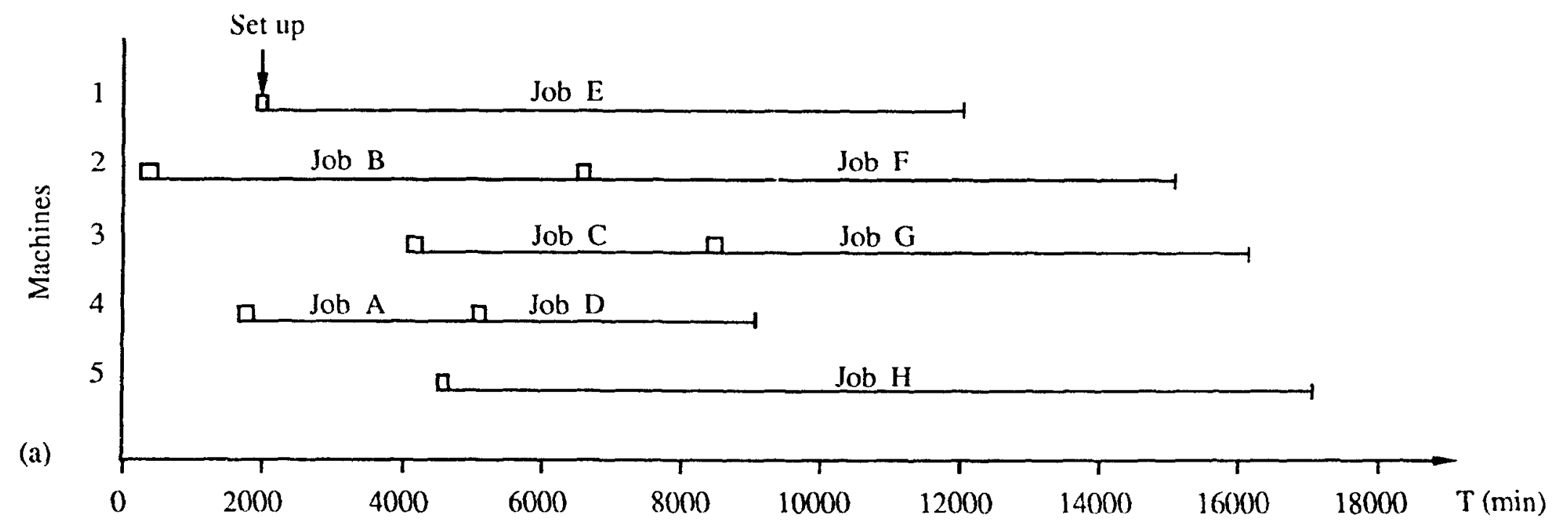

แ

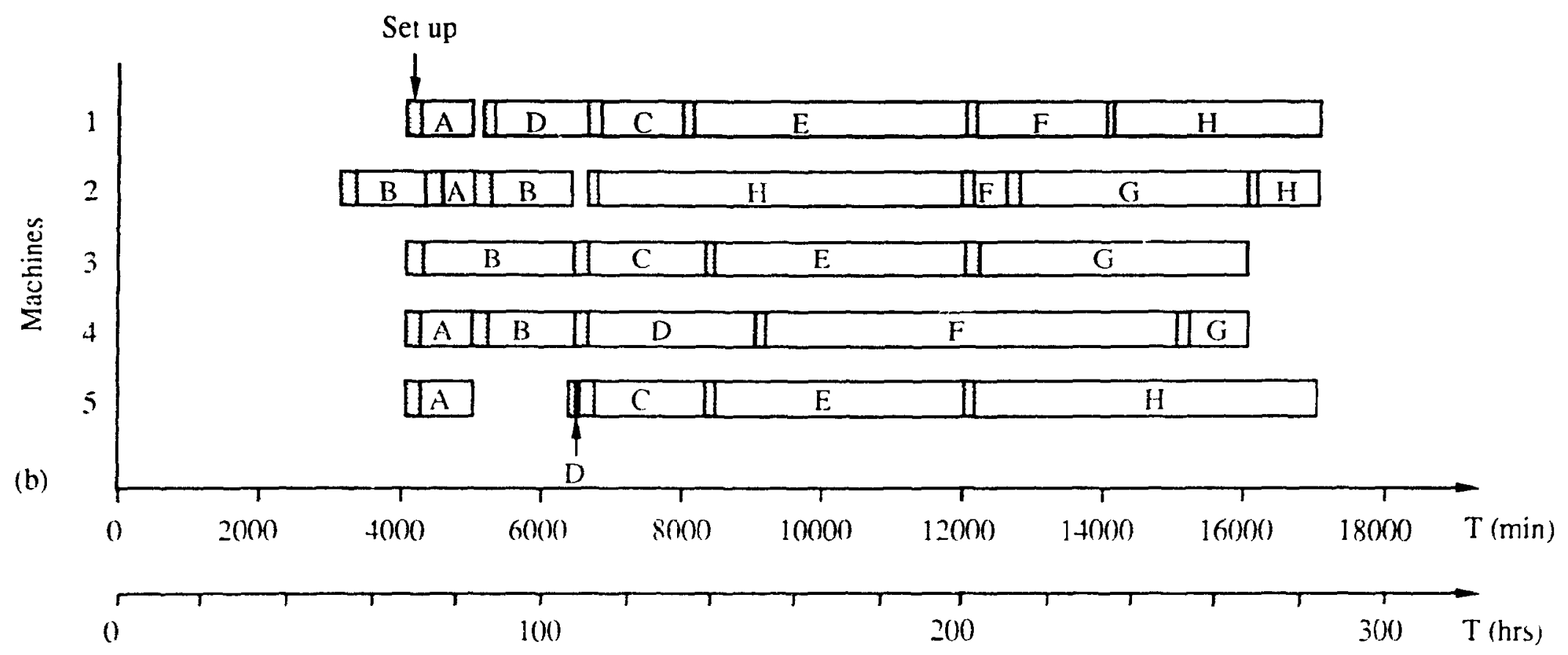

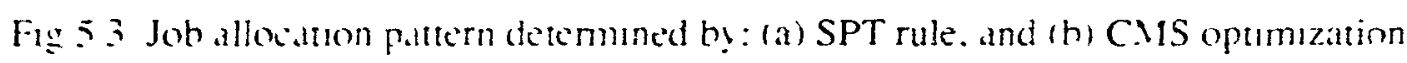




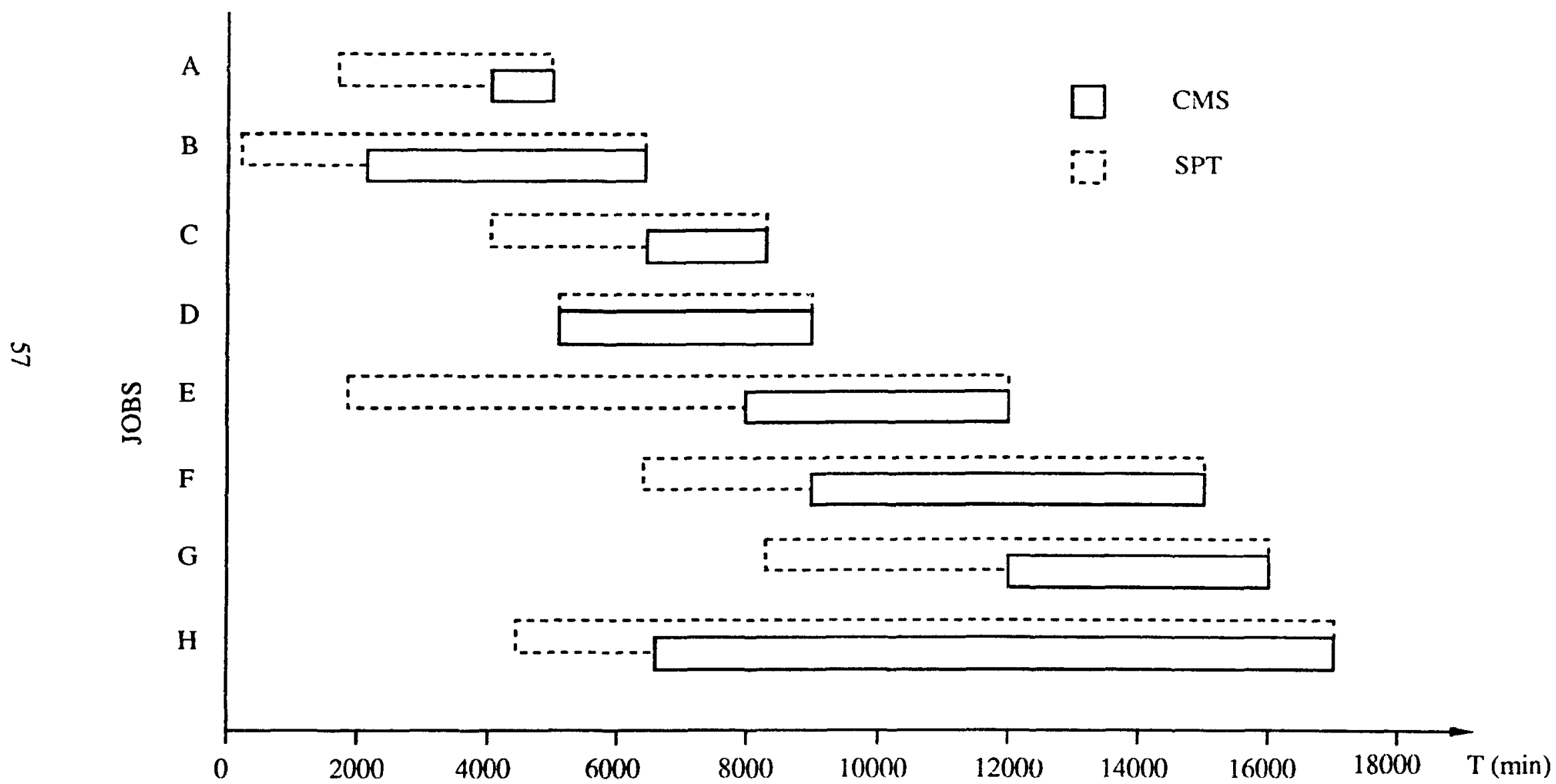

Fig 5.4 Starts and makespans of jobs determined by SPT rule and CMS algorithm 


\section{Chapter 6}

\section{Application of Algorithm to}

\section{Multiple Operation Job Shops}

\subsection{Analysis of the Problem}

In this chapter, the job allocation prorens involved in multiple oneratum folt shops will be considered. This is an extension of the single operation pullem The principles, L.P. formulation and the solution procedute an be aldepterl fen multiple operation jobs with minor modifications.

The machine tools in the factory are assumed to be grouped arcosting to the nature of processes e.g., tuming. milling, grinding efe. All job ate a summed to ge" through the different sections (operations) in a predetermuned seguenere There are alternative marhine tools in each section. The pusessing times. setup tumes. due dates, quantities, machine avalability and capability are known a moni fob 
allowation problems of this nature are typical for factories where the layout of mar hine tocks is arcording to the processes. By combining multiple operations the problem beromes more realistic and hence the applicability of solutions to jol, shops is appropriate. The optimization is carried out within each section, thus poviding a cummlative effect on the entire shop operations.

\subsection{L.P. Formulation}

T'he lincar programming model provided in section 4.2 is modified to suit the multiple operation problem. In addition to the nomenclature already provided, the sulscript lacts as the index for sections (operations). The linear programming morlel of the joh allocation problem within each partition $i$ (stage) is formulated with an objective to maximize the number of pieces $X_{1 j m l}$ of each job $j$ $\left(J=A, B, C^{\prime}, \ldots, N^{\prime}\right)$ produced on a machine tool $m(m=1,2 \ldots, M)$ at the opralung sertions $l(l=1,2, \ldots, L)$. While the machines in each section are not identical, a joh can be processed on more than one machine. Processing time $R_{\jmath m l}$ and selup time $S_{\jmath m l}$ are incurred when one unit of job $j$ is loaded on mahine $m$ at section l. The L.P. formulation for the job allocation problem is as follows: 


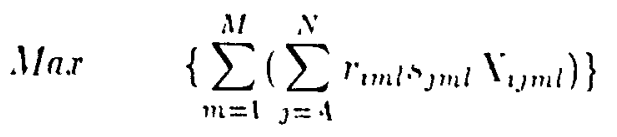

subject to:

$$
\begin{aligned}
& \sum_{m=1}^{M} r_{\imath m l} s_{3 m l} x_{\imath \jmath m l} \leq Q_{3} \quad J=A, B, \ldots, l \\
& \sum_{j=4}^{x} r_{i m l} \mid s_{\jmath m l} R_{\jmath m l} X_{i j m l} \leq T_{i m l} \quad m=1,2, \ldots \\
& X_{\imath \jmath m l} \geq 0 \quad \jmath=1,13 \ldots \ldots \\
& m=1,2, \ldots, 1 /
\end{aligned}
$$

$r_{i m l}=\left\{\begin{array}{l}1 \text { if machine } m \text { at section } l \text { is a valuble al stage } \\ 0 \text { otherwise }\end{array}\right.$

$s_{3 m l}=\left\{\begin{array}{l}1 \text { if machine } m \text { at section } / \text { is a apable of proressing job } J \\ 0 \text { otherwise }\end{array}\right.$

The machine availability index $r_{\text {mbl }}$ and the machine copalulits indes s,me ate responsible for climinating all the terms that enduce to zero, both in the ol ger tewe function and constraints. The first set of comsthaints cmumes that the quedulty produced at each stage is not more than the demand gnantity. The seromel sel of constraints restricts the total processing time on carh marhime fool mol fo rar and the available time on that machine. The last set in a non-negativity comblinint for the quantity of jobs produced in the stage. 


\subsection{Solution Procedure}

'The solution procedure described in section 4.3 is used here. An additional step is provided to link the different sections (operations). The solution procedure encompassing both the linear program and the heuristics is shown in Fig 6.1.

\subsection{Numerical Example}

Let. us consider a case of 6 jobs that has to undergo 3 operations (e.g., turning, milling and grinding). Each section (operation) has 4 machines and the jobs can be processed in any of the alternative machine tools. The processing times and the seluy times at different sections are given in Tables 1 and 2 , while the demand quantities and the due dates are shown in the Table 3. The Tables indicate also the machine tools that are not capable of processing a particular job.

The optimization problem can be stated as follows. For a case of $N=6$ jols, $M=4$ machines in cach section, the optimization problem based on CMS algorithm is defined for every stage with an objective to maximize the number of piecen of each job processed within a stage. Such an objective learls to maximum production rate and machinc utilization. Each job has to be processed in sections 1,2 and 3 , in that order. Production is in lots equivalent to the demand quantity within the due dates specified. The starting times are calculated by applying SPT rule backitirds from the due dates given and this provides a reference to define the stages. In this procedure the jobs are assumed to be non-preemptive and 


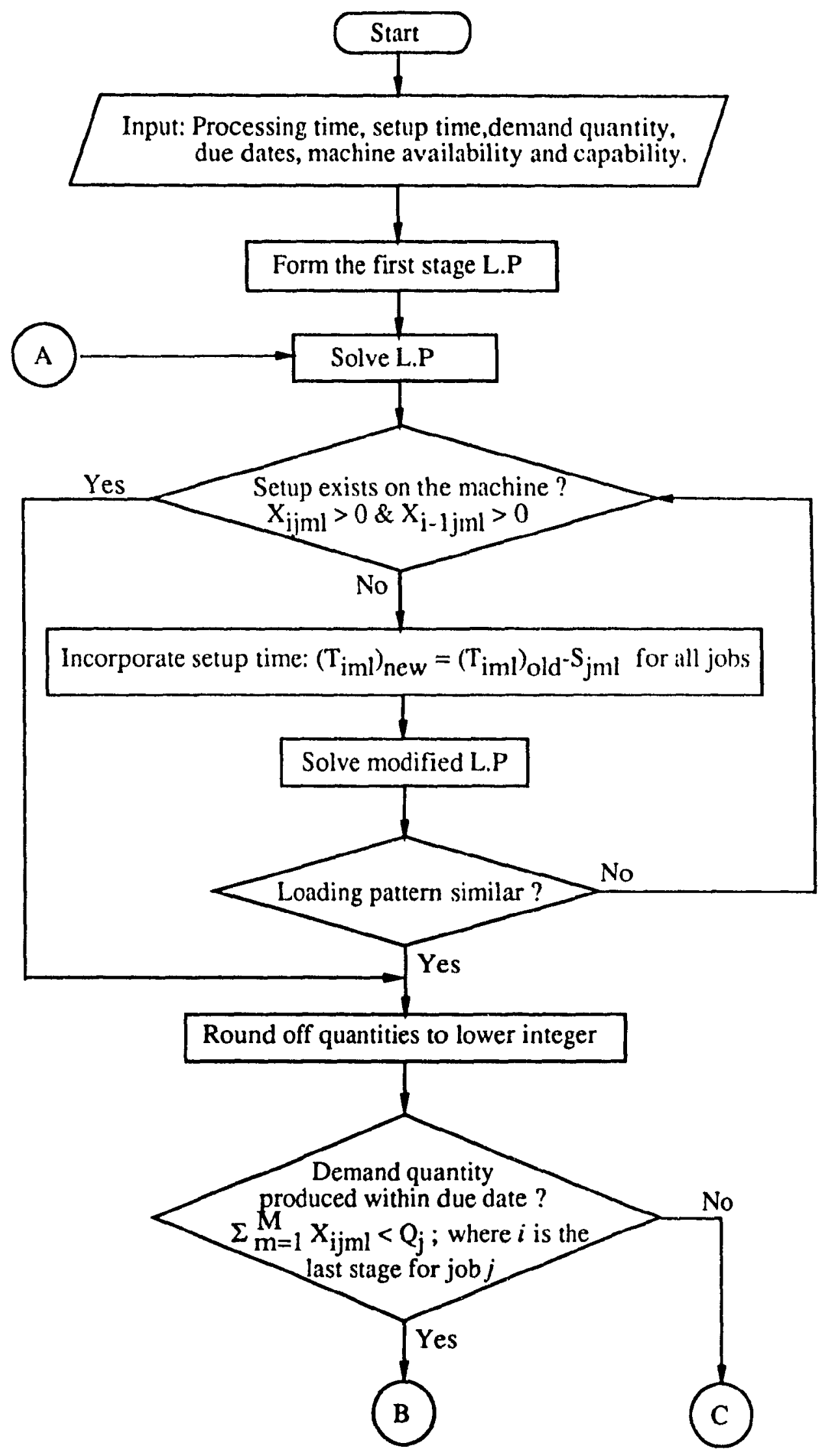

Fig 6.1 Flow chart for the solution procedure 


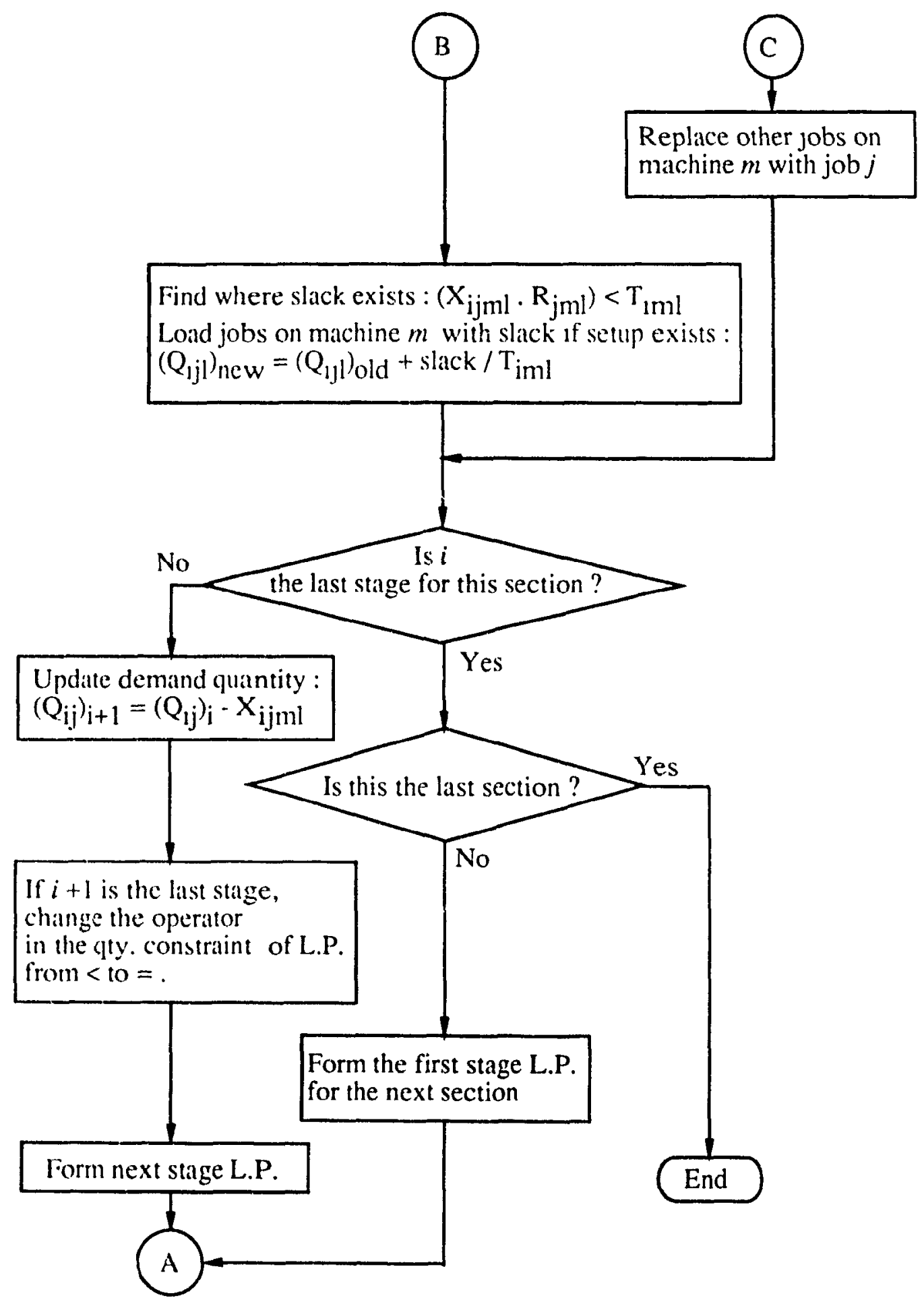

Fig 6.1 Flow chart of for the solution procedure (contd.) 
when two or more jols compete for the ame mathere the foh has hes the least

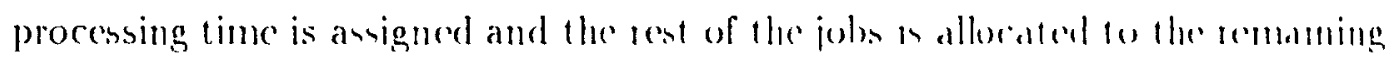
machines.

\subsection{Results and Discussion}

The rewults obtained by applying ('MS algorithm are promented in Thbles 61 to 6.6 and Figures 6.2 to 6.4 . As an example of the resultant jol, alloratom, ligh 6.2 shows the distribution of jobs on machine tooh in the fint serten. Ihe siple allocates cach job to one machine only, cansing unbalamed mathine leading By

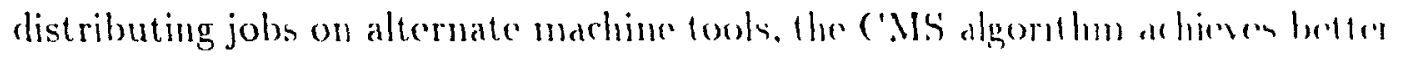
utilization of machimes. Table 6.1 shows ut hlization of mar hime fouls for all fhere sections. The utilization was calculated as the rotsu of time the mon hume in burs, to the time between the cntry of the first job and departue of the last job foum

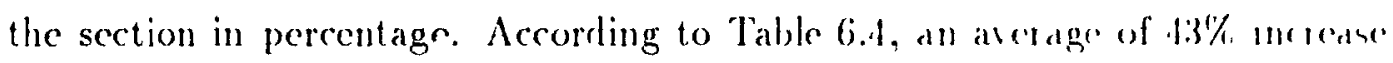
in utilization of machine tools for all three sertions was acheverd when ('WlS algorithm is applied (ave. $87.3 \%$ ), in comparison with SPT Mlle (ave. (il\%).

Another positive rffect of the application of ('MS algorithm in the reduction of completion dates of every job. in the presont esample. Fig. fi:3 provirlen, the Gantt diagram for jobs being processed in all theee sections. Fon tanty of presentation only the first and the last jol, are plotted, $\Lambda$ and F respectively. Pon cessing times for jobs allocated according to both SPT mle and (XIS algem thm 
Table 6.1: Processing times of jobs on machine tools

\begin{tabular}{|c|c|c|c|c|c|c|c|}
\hline \multirow{2}{*}{\multicolumn{2}{|c|}{$\begin{array}{c}\text { Machine } \\
m\end{array}$}} & \multicolumn{6}{|c|}{ Processing Times (min) } \\
\hline & & $A$ & B & $\mathrm{C}$ & $\mathrm{D}$ & $\mathrm{E}$ & $F$ \\
\hline \multirow{4}{*}{ 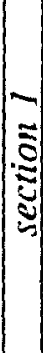 } & 1 & 1.0 & 0.98 & 1.8 & 3.0 & 3.2 & 3.92 \\
\hline & 2 & 1.5 & 1.0 & 1.85 & $\dagger$ & 3.0 & 3.90 \\
\hline & 3 & 0.95 & 1.5 & 2.0 & 3.3 & 3.4 & 4.05 \\
\hline & 4 & t & 0.95 & 1.9 & 2.95 & 3.25 & 3.95 \\
\hline \multirow{4}{*}{$\mid \begin{array}{l}n \\
5\end{array}$} & 1 & 2.1 & 1.1 & 2.7 & 4.1 & $t$ & 2.7 \\
\hline & 2 & 2.25 & 1.0 & 2.8 & 4.2 & 3.5 & 2.5 \\
\hline & 3 & 2.2 & $\dagger$ & 2.75 & 4.25 & 3.35 & 2.8 \\
\hline & 4 & 2.0 & 1.15 & 2.85 & 4.3 & 3.2 & 2.6 \\
\hline \multirow{4}{*}{ 尚 } & 1 & 7.4 & 6.5 & 9.2 & 7.6 & 8.75 & 7.35 \\
\hline & 2 & 7.3 & 6.3 & 9.1 & 7.5 & 8.8 & $\dagger$ \\
\hline & 3 & 7.2 & 6.2 & $\dagger$ & 7.3 & 8.5 & 7.3 \\
\hline & 1 & 7.35 & 6.35 & 9.15 & 7.55 & 8.7 & 7.4 \\
\hline
\end{tabular}

t-the machine is not capable of processing the job 
Table 6.2: Setup times of jobs on machines

\begin{tabular}{|c|c|c|c|c|c|c|c|}
\hline \multicolumn{2}{|c|}{ Machine } & \multicolumn{6}{|c|}{ Setup Trmes (min) } \\
\hline & $m$ & A & B & $\mathrm{C}$ & $\mathrm{D}$ & $\mathrm{E}$ & $\mathrm{F}$ \\
\hline \multirow{4}{*}{ 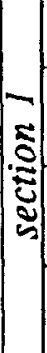 } & 1 & 60 & 75 & 105 & 80 & 55 & 75 \\
\hline & 2 & 50 & 70 & 100 & $\dagger$ & 60 & 70 \\
\hline & 3 & 65 & 65 & 90 & 55 & 50 & 80 \\
\hline & 4 & $t$ & 100 & 90 & 95 & 65 & 65 \\
\hline \multirow{4}{*}{ 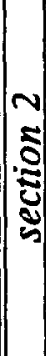 } & 1 & 80 & 105 & 85 & 100 & $\dagger$ & 100 \\
\hline & 2 & 85 & 120 & 90 & 90 & 120 & 110 \\
\hline & 3 & 83 & $\dagger$ & 95 & 95 & 115 & 100 \\
\hline & 4 & 90 & 110 & 80 & 95 & 110 & 105 \\
\hline \multirow{4}{*}{$\mid \begin{array}{l}m \\
5 \\
5 \\
5 \\
5\end{array}$} & 1 & 60 & 45 & 90 & 70 & 65 & 100 \\
\hline & 2 & 65 & 50 & 100 & 75 & 60 & $t$ \\
\hline & 3 & 70 & 65 & $t$ & 80 & 70 & 105 \\
\hline & 4 & 65 & 60 & 100 & 70 & 65 & 95 \\
\hline
\end{tabular}

t-the machine is not capable of processing the job 
Table 6.3: Demand quantities and due dates

\begin{tabular}{|c|c|c|c|c|c|c||}
\hline Jobs & $A$ & $B$ & $C$ & $D$ & $E$ & $F$ \\
\hline Quantuly & 600 & 800 & 1200 & 700 & 850 & 900 \\
\hline Dur Inte (mm) & 12000 & 15000 & 23000 & 19000 & 16000 & 16000 \\
\hline
\end{tabular}

are shown for companison. Sime each section is solved sequentially, reduction III completion time has a cummlative effert and the due dates are significantly shontoned This anomits to ddditional avasalble free capacity and condd be used 10 procese ofher johs. The redurtion in complotion dates is linked to shorter makespam which can le arhered when CMS optimization algorithm is appled. This is illustuded in Fig. 6.4 and by the data in Table 6.5. It can be scen from this Thale. that a reduction m makespan between $5.7 \%$ and $73.8 \%$ was achieved for induridual jobs. The reduction in makespa' of course, the result of the distribution of jols on machines.

As experted. the maximum ontput objective results in increased production Inte for all sect ons as indicated in Table 6.6. The maximum increase of $43.6 \%$ was "hiverd in sertion \# 3. One should note, that although in the present example each joh passes through all the sections, in general a job may be scheduled to by pass certain operations and to be processed in the remaining sections only.

The reduction in computational time which is derived as a result of decom- 


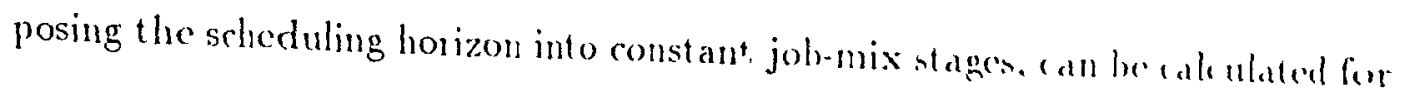
cvery section (operation), usmg the expression derived in 5.32.2. The mumber of constraints present in the L.P., when all stages ate agenededed, for nectume 1. 2 and 3 are 36.31 and 38 respectively. The number of constrants prement in the stages:

for section \# $1:\{3,5,6,7,7,8,5,5\}$

for section \#2: $\{5,6,5,5,5,6,7\}$

for section \# 3: $\{5,6,6,7,7.8,8,8\}$.

Hence the computational saving for cach section in:

$$
\begin{aligned}
& R_{T 1}=\frac{36^{3}}{3^{3}+5^{3}+6^{3}+7^{3}+7^{3}+8^{3}+i^{3}+5^{3}} \Rightarrow 2.7 .7 \approx 2(i \\
& \left.R_{T_{2}}=\frac{31^{3}}{5^{3}+6^{3}+5^{3}+3^{3}+5^{3}+6^{3}+7^{3}} \Rightarrow 31\right)=31 \\
& R_{73}=\frac{38^{3}}{5^{3}+6^{3}+6^{3}+7^{3}+7^{3}+8^{3}+8^{3}+8^{3}} \Rightarrow 197.5 \approx 20
\end{aligned}
$$


Table 6.4: Comparison of machine utilization

\begin{tabular}{|c|c|c|c|}
\hline \multirow{2}{*}{\multicolumn{2}{|c|}{$\begin{array}{c}\text { Machine } \\
m\end{array}$}} & \multicolumn{2}{|c|}{ Machine Uttlizatıon \% } \\
\hline & & $S P T$ & $C M S$ \\
\hline & 1 & 46.6 & 97.9 \\
\hline$=$ & 2 & 92.1 & 89.3 \\
\hline : & 3 & 48.9 & 95.3 \\
\hline & 4 & 71.3 & 89.3 \\
\hline \multirow{4}{*}{ 约 } & 1 & 50.7 & 94.2 \\
\hline & 2 & 49.4 & 57.2 \\
\hline & 3 & 46.7 & 46.7 \\
\hline & 4 & 62.5 & 97.0 \\
\hline \multirow{4}{*}{ : } & 1 & 35.6 & 100.0 \\
\hline & 2 & 72.8 & 99.7 \\
\hline & 3 & 77.2 & 85.9 \\
\hline & 4 & 78.8 & 94.6 \\
\hline
\end{tabular}


Table 6.5 ('omparison of completion dater and makespam

\begin{tabular}{|c|c|c|c|c|c|c|c|}
\hline \multicolumn{2}{|l|}{ Jobs } & $\Lambda$ & B & $C^{\prime}$ & 1) & $E$ & ri \\
\hline Completion & $S P T$ & 9691 & 10682 & $2: 3000$ & 16000 & $19(1) 10$ & $19(10) 10$ \\
\hline$D_{a} t_{t} \rightarrow(m m)$ & CAMS & $6.58: 3$ & 5570 & 1.59990 & $15: 27$ & 1.3912 & $111: 31$ \\
\hline Makespan & $S P T$ & $10: 533$ & 12780 & 20600 & $1: 3176$ & $16 i 3: 36$ & 157111 \\
\hline$(m m)$ & CMS & $18: 36$ & $3: 3550$ & $1: 3680$ & 12.783 & $1: 3219$ & $|\| N| \mid$ \\
\hline Reductuon & $\%$ & 52.8 & 73.8 & $3: 3.8$ & 5.7 & 18.9 & 30.9 \\
\hline
\end{tabular}

Table 6.6: Comparison of production ale

\begin{tabular}{||c|c|c|c||}
\hline \hline \multirow{2}{*}{ Op.Scction } & \multicolumn{3}{|c||}{ Production Rale (prss/mm) } \\
\cline { 2 - 4 } & SPT & (MMS & Imerast $/ / 1$ \\
\hline 1 & 0.838 & 1.139 & 35.9 \\
\hline 2 & 0.620 & 0.744 & 20.1 \\
\hline 3 & 0.267 & 0.383 & 43.6 \\
\hline
\end{tabular}




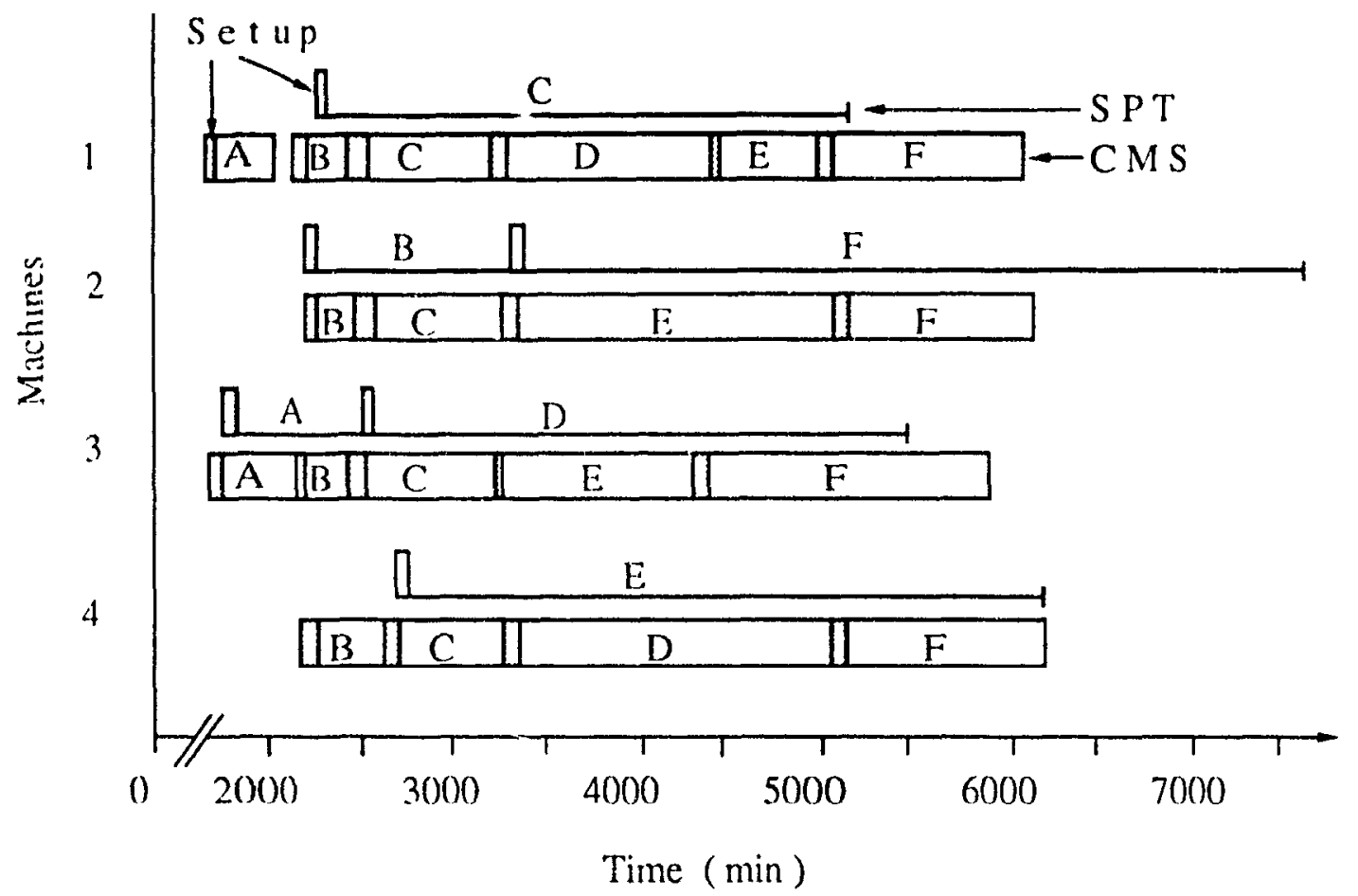

Fig 6.? Allociation of jobs at section \# 1 determined by SPT rule and CMS algorithm 


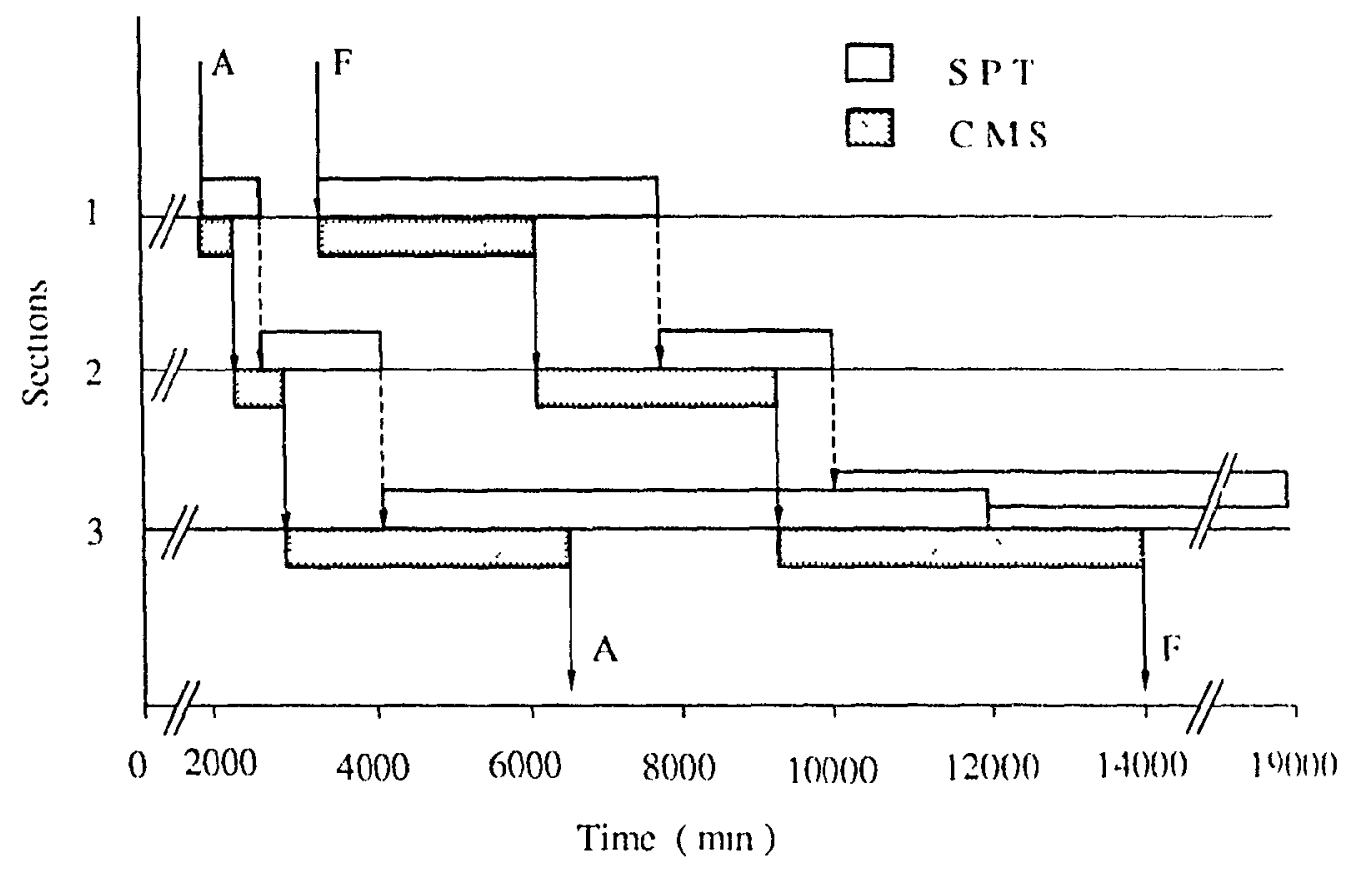

Fig 63 Gant chart representing the flow of job A and job F for SPT rule and CNS alyon 1 llm 


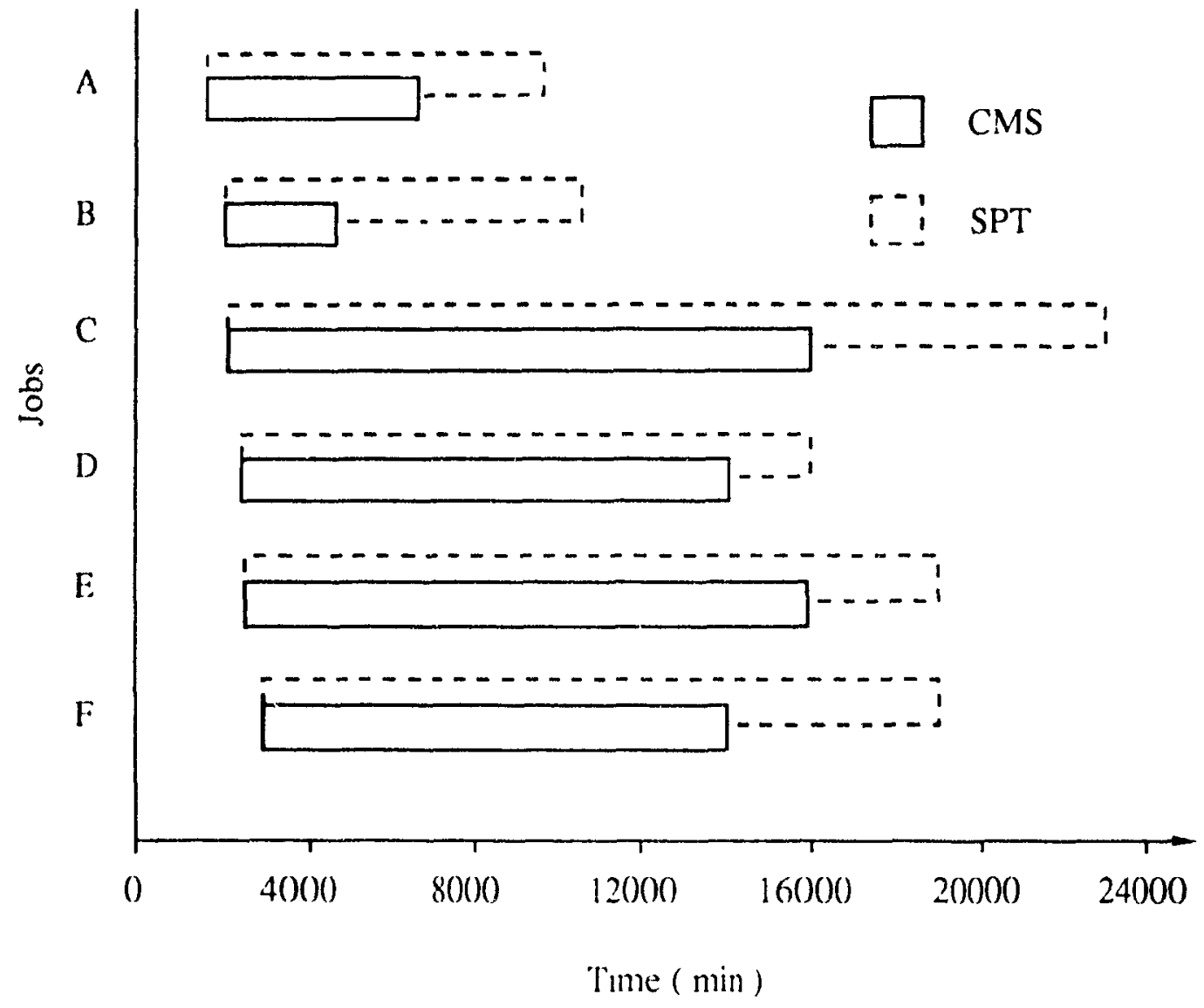

Fig 6.4 Completion dates and makespan of jobs resulting from SPT rule and CMS algorithm 


\section{Chapter 7}

\section{Integration in Intelligent}

\section{Manufacturing Systems}

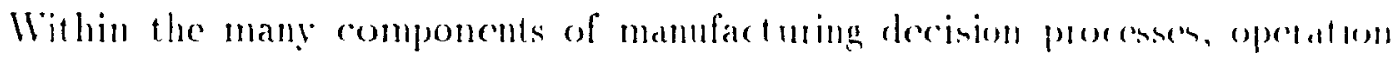
scheduling can be pereaived not only as an important lonk in the chain, hut "rent as a hub of the informalion system linking the activites associated with the pro duction processes. The information flow roncerms bot he the decinion poueneses and the material flow i.f., physical execution of orders. Howerer, the hast amonnt of raw data existing in present day management information systems is not used fon optimization of production management, a parlicularly difficult task comsirlening that this is a dynamically changing environment.

The usefulness of integrating the capability of intelligent systems with traditional information sy.stems has becn recognized already by Tseng and ()'(ommen [18], while Lu [19] proposed a framework for integration of heuristic durd deter- 
ministir knowlentge for enginereng decisions.

The present procedure for dynamir optimal job allocation using the CMS algonithm links existing computerized information system with rombined detemministic and heuristir solution. Thus, the procedure extends the functions covend by the information system to operational level derision.

The link to the existing management information system is accomplished though the matufacturing resource planning system (MRP II). It contains, as one of its five function, the master production schedule (MPS), the others being: Iegluirements plamning, capacity planning, shop floor control and cost control (production accomnting) (Flapper et al. [20]).

The MPS' module provides a timetable specifying what components, in what gunntities are needed and when. However, MPS does not extend its functions to operations scheduling, i.f., job sequencing and job-resource allocation. In practice, while sequenring is done using some priority rules, the decision concerning jol, allocation on machine tools is left to the forcman on the shop floor. And yet, these functions are of critical inportance for shop efficiency which affects its actual capacity and subsequently the throughput.

The CMS algorithm can be incorporated into the MPS module, and then, linked to other functions of MRP II system. Such an integration would function in the following way: the MPS module generates the master production schedule, which triggers the relcase of production orders for all components which have to be processed in the shop. Based on the production orders and the data 
available from the manufacturing database, the ('Ils algotithm gemeden the job allocation scherdule

An important factor in the integration of ('MS algerithm with the Mlls/Alh' Il system is the type of information and the compathility of data. Fin generale a schedule, MPS uses information on domand quantities and delivey dates 'llhe CMS algorithm uses the same infomation, In addition to which it usen also the machine availability and capability data from the manufartuing databuse. While the algorithm is reasonably independent fiom the MRP II modules. the structure of the data, the arcess arras of the alguilhm and the hremoln of the algorithm function should be taken into acromint whle intregrating.

The integration of the CMIS job allocation algorithm with the MIS's morluke (which also contains process planning information) condd he, and indered slombl be, extended to other components of the manufactuing decision system, such as: scheduling and allocation of maintenance, personmel and equipment on machincs, scheduling (and in some cases also allocation) of components processed on vanions machines to quality control stations and/or assigning quality control insperfons to machine tools. Further extension would also inter face scheduling of matcoial release and material handling (physical) to be synchronized with the job-machine allocation and sequencing.

All these links would have the fecdback loops equipped with loinuing self correcting adaptive capability for the use of CMS algorithm for pousible. rescheduling and reallocation of jobs. Such a design would make full use of the: 
dyunmuc eptimzatuon capabilities of the CNS algorithm. These arcas are the obvious topies for futue sescarch and development in an offort towards developing computer integrated intelligent manufacturing systems - an intelligent CMM. 


\section{Chapter 8}

\section{Conclusions and}

\section{Recommendations for Further}

\section{Study}

\subsection{Conclusions}

A new method which has been developed to optimize job allocation on machine tools in a time-dependent environment, cuhaness the eflicieney of production planning systems by generating more realistic schedules. Besides, since the jol, allocation function is closely related to other components of a mamnfarturing system, the schedules obtained by using the ('onstant Job-Mix Stage (CMSS) algorithm aids in the efficient functioning of the related departments like maintenance, quality control etc. As the CMS algorithm targeted the key parametess 
of a machine shop (1.q. production rate, makespan) for improvement, the performane of the overall factoty is amoliorated.

The Aeromposition scheme partitions the scheduling horizon into stages of combant job-mix. The CMS algorithm based on this scheme uses linear programming within cach stage to allocate jobs on machine tools, and associated hem istus fo acomnt for setup times, due date enforcement, integer solutions and shark adention while optimizing job distribution. The procedure proceds from stage fostage, the output of one stage being the input of the next. This forms a dynamic scheme of optimization which links the whole problem.

Thuer different cxamples were dealt with in detail to demonstrate the appliintion of ('MS algorithm. All of them concerned multiple jobs to be allocated on a number of machine tools, each with different capacities and capabilities. Such situations ate quite typical of many job shops in which machine tools are laid out acording to their processes. The following conclusions can be drawn from these applications:

1. The susults of the CNSS algorithm, when compared with those of the aggregated approarh and SPT rule indicate that better utilization of machine tools can be achieved.

2. The compressed schedule along with high utilization of machine tools brings about a significant reduction in the makespan of individual jobs. As a result the jobs spend less time on the shop floor leading to greatly reduced work- 
in-process (WIP) inventory.

3. Improved production rate (throughput) is an impontant henelit denived from the application of the C'MS algorithm. In the case of single operat tion jobs the increase 21 production rate is measured for all the jobs and machines together. For the multiple operation case, improvement in pro duction rate is noted for each sertion thus contributing to the producturity of the overall shop.

4. The CMS algorithm provides a compressed schedule; while selendulung is carried out fom the starting times, carly shipment dales for jolss for or ders) are obtained. When scheduled from the due dates the (Mis algumbhm provides late start dates. In both cases the spane time which in marle avalable because of the compressed schedule, can be used to process allitional jobs.

5. It is possible to apply the CMS algorithm to both single and multiple operation job shops. In the latter case the machine took arr grompert in sections according to their operations.

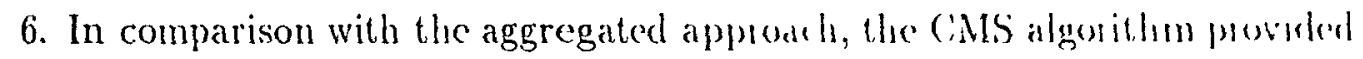
a significant savings in computational time reguined to solve the joh allecation problems. Using the expression developed to calculate such savings: in time, it can also be concluded that, the savings in comput at iemal tmme increases when the stages contain fewer jols. 
7. Job allocation problems solved using the CMS algorithm, open the pussibility of combining deterministic and heuristic procedure with malnagement information systems, specifically the master production schedule of MRP II, to arrive at a solution for shop floor cont rol.

8. As the CMS algorithm aids the job allocation decision process in a production planning function, it provides an efficient control when integrated with the other components of manufacturing system like maintenance, guality control and material release. Such an integrated system enhances the antomation of various decision making processes.

\subsection{Recommendations for Fu'ther Study}

One of the important feature of job allocation using the CMS algorithm is the distribution of setup times. While in the common practice of assigning a job to machine with SPT, only one setup is needed for the full processing time of a job, this is not the case with the CMS method. In the new mothod setups are assigned to various machines according to the optimized solution, whene setup times are taken into account. Since the optimization is carried out within cach stage without considering the allocation in the previous stage, this may result in multiple setups for a single product on a particular machine at different periorls. If such a situation is encountered, allocation of jobs on each machine can be shuffled so that fewer setups are necded. However, due to this shuffling the 
arrival and due times of jobs can change leading to the redefinition of stages. In surh circumstances, a comparison between CMS algorithm allocation and the shuffled schedule can be carried out with a suitable performance criterion.

In the CMS algorithm jobs are assumed to be preemptive. Because of the multiple setups problem mentioned earlier, it may be wortbwhile to conduct a comparison between premptive and non-preemptive scheduling with makespan criteria. The non-premptive schedule is obtained by assigning jobs on only machines which are free to load while allocated to subsequent stages.

In the join allocation schedule, the setup times are accounted for, independently of the processing times. That is, the setup times are assigned based on the initial solution and often the job allocation before and after the setup time assigument are the same. This is because, once the setup time is deducted from the total available time, optimization is carried out for the remaining time. In order to consider collectively both setup and processing times in the schedule, break even analysis can be used. The equation for each machine will consist of a fixed setup time and a variable processing time which is a direct function of the quantity processed. Choice of machine to process a particular job is arrived at by comparing these equations and obtaining the break even quantity.

Another interesting topic for future study is the transfer quantity of the jobs between the different operations in a job shop. This means one can produce a process batch (which equals the demand quantity, as is in all our cases) and move to the next operation, or in smaller lots called transfer batches. Transfer batch 
is used by JIT encept, where the objective is to achieve a one-unit processing batch. Such transfer batch movement from one operating section to another affects the time-partitioning and the duration of partitions becase the stagen ate defined by the job arrivals and departures. This consept of changing a tidnsfer batch can be applicable to jobs of high demand quantity and processing 1 immes.

Since the linear programming formulation of the job allocation problem is similar to the transportation model, the possibility of devising a solution procedure using the triangularity structure can be studied. Some of the steps in the CMS algorithm are carried out manually. The scheruling algonithm can be fully computerized such that it can either form a part of an cxpert system on scherlul. ing, or be integrated with other functions of the Production Sy'stem. While the former will be a dedicated scheduling system to advise on the alloration function in different circumstances, the latter will be a part of planning and comtrol function enhancing the automation of the production management, system 


\section{Bibliography}

[1] CiRAVES. S. ('.. 1981, A reviow of Production Scheduling. Operations Resrarch $29(4), 646-675$.

[2] IIORN, W. A., 1973, Minimizing Average Flow Times with Parallel Ma(hunes. Oprentions ressarch, 21(3), 846-8.47.

[3] POWELL. N., 1970, Production Planning, Scheduling and Inventory Control (London: The Macmillan ('ompany).

[1] LAWLER, E. L.., and MARTEL, C. U., 1989, Premptive scheduling of two uniform machines to minimize the number of late je'ss. Operahons Rescarch, $37(2), 311318$.

[5] MrNAli(ill'TON, R., 1959). Scheduling with Deadlines and Loss Functions. Mlanage ment Serence, 6, 1-12.

[i] D)AN'TZICi. (i. B., 1959. On the Status of Multi- Stage Linear Programming Problems. Mlanagement Socuner.6 (1), 53-71. 
[7] LEON S. LASDON., 1970, Optimiation Theory of Larqu Siystem. (Nien York: Marmillan).

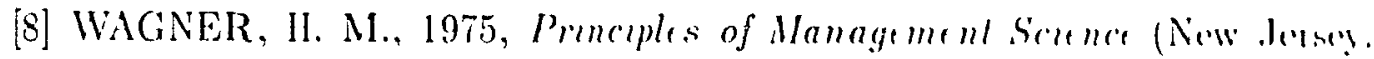
Prentice-Hall, Second Edition).

[9] NASR. N., and ELSAYED, E. A., 1990, Joh Shop S'cheduling with Altemative Nachines. Internatoonal Journal of Produchon Resurrh,28 (9), 1595-1609.

[10] JAIN. S. K. SCOTT. K. L, and VASOLD. E. (i. 1978, Orter Bush Bal-

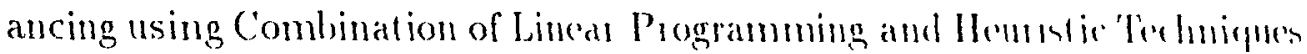
Interfaces, 5567 .

[11] DORSEY. R. (.., HODGSON. T. J.. and RATLIFl. II. 1)., I9T, A Pu. duction Scheduling Problem with Batch Procousing. Oprotoms Rrorarrh 22 (6), $12\lceil 1-1279$.

[12] IWATA, K., MUROTSU, Y., OBA, F., and OKAMURA, K., I9sol, Sulution of Large-Scale Scherduling Problems for Job Shop, Type Machuning Systents with Alternative Machine Tooks dnnals of CIRP, 29 (1), 333.-3338.

[13] DILTS, D. M., 1991, The Sensitivity of Set-11] ('ont Estimation on lhe problem of Joint Lot Sizing and Scheduling. International fournal Productoon Research, $29(1), 77-93$. 
[14] ALAEE, M., 1978. Bfhrient. Loarling of Marhine Tools in Intermit tent Manufacturing, M.Eng. Project Report, McGill University, Canada.

[15] (ANREY, M. R., JOIINSON, D. S., and SETHI, R., 1976, The complexity of Howshop and jobshop scherduling. Mathematical Opcrotions Rescarch. 1, $117-129$.

[16] IIILLIER. F. S., and LIEBERMAN. G. J., 1990. Introduction to Oprat.ons rusearch (McGiraw-Ilill, $5^{\text {th }}$ ct.)

[17] (30).DR TTT, E. M., 1990, The Theory of Constrants. (North River Press Inc., (Goton-on-Hudson, New York).

[IS] TSLENG, M., and O'CONNOR, D., December 1986. Augmenting C'IM With Intelligent Systems, Kinouledgr-Based Expert Systems for Manufactureng, ASME, PED-Vol. 24, 3-10.

[19] LU. S. ('-Y'., Deremeber 1986, Knowledge-Based Expert Systems: A New Ilotizon of Manufacturing Antomation, Linowlrdgr-Based Expert Systems for Manufacturing, ASME, PED-Vol. 24, 11-23.

[20] FlAPPER, S. D. P., MLLTENBURG, G. J., and WIJNGAARD, J., 1991, Embedding JIT into MRP. International journal of production research, $29(2), 329-3.41$.

[21] BAIIL, II. C., TA.J, SIIARAM., and CORCORAN, W., 1991, A linearprogramming model formulation for optimal product-mix decisions in 


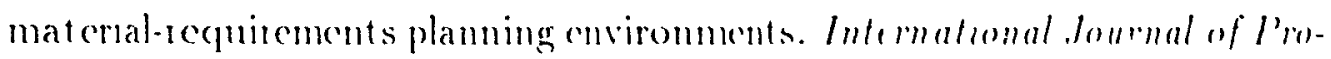
duction Rescarch. 29(5), 18:2.)-1031.

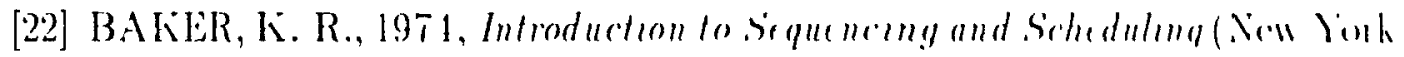
John Wiley).

[23] BUFFA, E. S., and SARIN, R. K.. I9ST, Modern Foduchon (Operaloms Management, (New Tork: John Wiley \& S Soms, $s^{\text {th }}$ or )

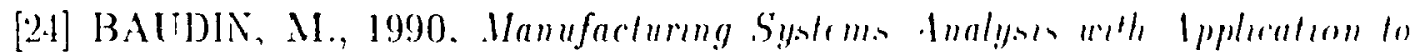
Production Schedulang, (New Jerse? Youndon P'uss)

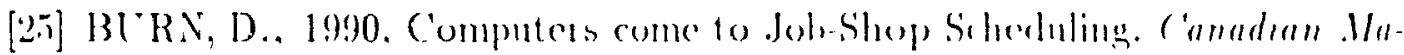
chmery and Metal Ilorkmg. 20-21.

[26] CONWAY. R. W., MAXWELL. W. L.. and MILLER, L. W.. IGfit.Thom" of Schedulung (Roadung, Mass.: Adrlison- Menley) Mp T. 79.

[27] FARN, C. K.. and MUHLEMANN. A. P., 1979. The Dytamin Asperts of a Production Scheduling Problem. Intermotoonal Journal of Podurtoon Risearrh, 17 (1), 15-21.

[28] GROOVER, M. P., 1987, Automation, Produrlom Systome, and Computu Integrated Manufacturing (Now Jetsey. Pention-Hall)

[29] GROOVER, M. P., and ZIMMERS, E. W., 1984, (AI) ("AM ( Ninw Jerny" Prentice Ilall). 


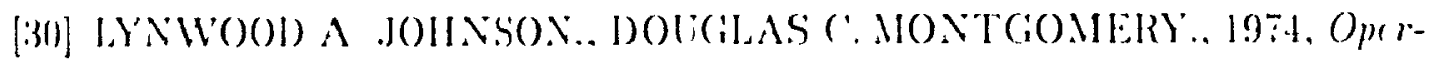
atmos Rrsearch an Produchoon Planmung. Schedulang and Inrentory Control (Now Yonk. John Wilcy \& Sons) pp 315-34.9.

[31] MAC:BB:III, D. K., 1989, ddranced manufacturang: startegy and managememt, (IFS PMb)

[32] MILTENBUR(i, J., and WIJNGAARD, J., 1991. Designing and phasing III Just-1n-time production systems. International journal of production irstarch 29(1), 115-1:31.

[33] PIILLIPS, I). T., RAVINDRAN. A., and SOLBERG. J. J.. 1976. Operahons. Ressarrh (Now York: John Wiley \& Sons).

[31] P'RA BHII. P., and WANG. H.P., 1991, Algorithms for Computer Aided Gen'Intiur Plocess Planning. International Journal of Advaned Manufacturng Tirhnology. 6 (1), 3-15.

[35] RONEN, B.. and STARR, M. K., 1990, Synchronised Manufacturing as in Ol'T: From practice to theory. Computers Industrial Engmeering, 18 (4), $585-600$.

[36] SC'HROEDER. R. G., 1981, Opcratıons Management (New York: McGrawIli!l Book ('ompany).

[3i] SilMON FREN('II. 1982, Srquencing and Scheduling: An Introduction to the Mathematies of the Job-Shop (New York: John Wiley \& Sons) pp 15-17. 


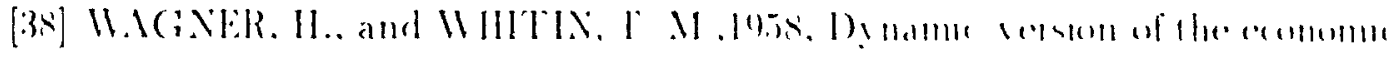

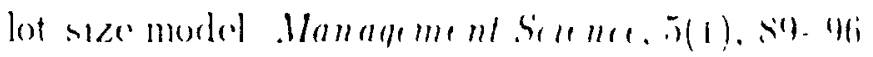

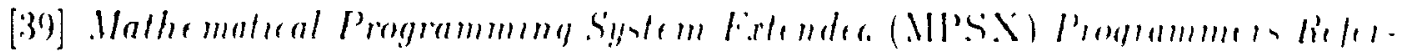

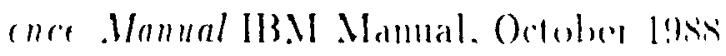


Appendix A

Sample of Job Control and Data

Cards for MPSX 


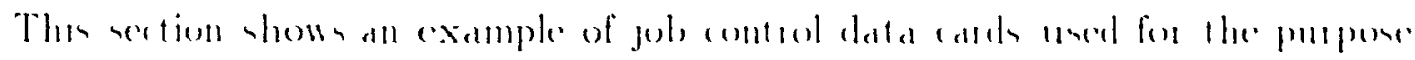

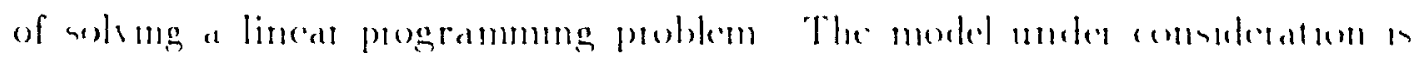

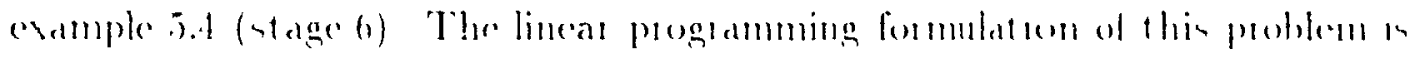
as follows:

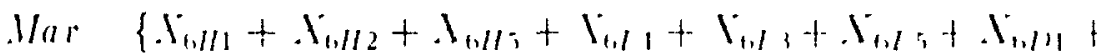

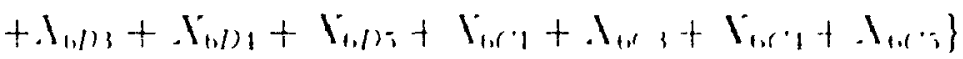

.ubject to.

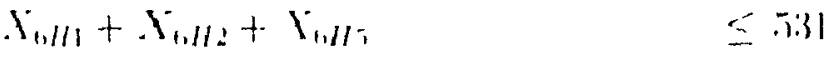

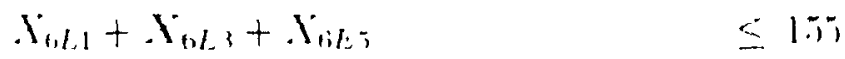

$$
\begin{aligned}
& X_{(, D)}+X_{(, 2) 3}+X_{(, 2) 1}+X_{(, 2) 5} \leq X(i)
\end{aligned}
$$

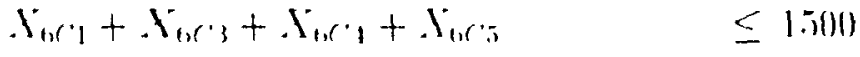

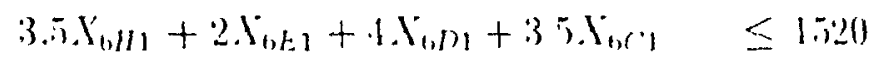

$$
\begin{aligned}
& 3.2 X_{6,12} \quad \leq 1 \% 6(0) \\
& 2.1 X_{6 E 3}+4.3 X_{6 D 3}+2.7 X_{61} \cdot 3 \quad \leq 1650 \\
& 3.7 X_{6 D 24}+3.9 X_{6 C 1} \quad \leq 1 \times 60 \\
& 3.1 X_{6 / 1} 5+225 X_{6,25}+4.2 X_{6,2)}+3 X_{6,5} \leq 16(60)
\end{aligned}
$$

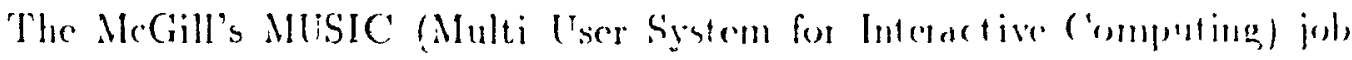
control cards followed by MPSX (Mathematical Programming and System lix. tended) dat a cards are provided in the following two pages. 
/INFO MVS R(MUSIC) CL(40)

// EXEC MPSX

//MPSGO.SYSIN DD *

PROGRAM

INITIALZ

MOVE(XPBNAME,'LINEAR')

MOVE (XDATA,'JIT6')

CONVERT('SUMMARY')

BCDOUT

SETUP('MAX')

MOVE(XOBJ,'QUANTITY')

MOVE(XRHS, 'BVECTOR')

PICTURE

PRIMAL

SOLUTION

PEND

//MPSGOX.SYSIN DD *

NAME JIT6

ROWS

N QUANTITY

L ROW I

L ROW2

L ROW3

L ROW4

L ROW5

L ROW6

L ROW7

L ROW8

L ROW9

COLUMNS

$\mathrm{X} 6 \mathrm{HI}$

QUANTITY 1.

X6H1 ROW5 3.5

X6H2 QUANTITY 1.

X6H2 ROW6 3.2

X6H5 QUANTITY 1.

X6H5 ROW9 3.1

X6E1 QUANTITY 1.

X6E1 ROW5 2.

$\begin{array}{lll}X 6 E 3 & \text { QUANTITY } 1 . \\ X 6 E 3 & \text { ROW7 } 2.4\end{array}$

X6E5 QUANTITY 1.

X6E5 ROW9 2.25

X6D1 QUANTITY 1.

X6D1 ROW5 4.

ROW1 1.

ROW1 1 .

ROW1 1 .

ROW2 1.

ROW2 1.

ROW2 1.

ROW3 1. 


\begin{tabular}{|c|c|c|c|}
\hline X6D3 & QUANTITY 1. & ROW3 & 1. \\
\hline X6D3 & kOW7 4.3 & & \\
\hline X6D4 & QUANTITY 1. & ROW3 & 1. \\
\hline X6D4 & ROW8 $\quad 3.7$ & & \\
\hline X6D5 & QUANTITY 1. & ROW3 & 1. \\
\hline X6D5 & ROW9 4.2 & & \\
\hline $\mathrm{X} 6 \mathrm{Cl}$ & RUANTITY 1. & ROW4 & 1. \\
\hline $\mathrm{X} 6 \mathrm{Cl}$ & ROW5 $\quad 3.5$ & & \\
\hline $\mathrm{x} 6 \mathrm{C} 3$ & QUANTITY 1. & ROW4 & 1. \\
\hline $\mathrm{X} 6 \mathrm{C} 3$ & ROW7 2.7 & & \\
\hline $\mathrm{X} 6 \mathrm{C} 4$ & QUANTITY 1. & ROW4 & 1. \\
\hline $\mathrm{X} 6 \mathrm{C} 4$ & RoW8 $\quad 3.9$ & & \\
\hline XKC5 & QUANTITY 1. & ROW4 & 1. \\
\hline XKC5 & ROW9 $\quad 3.0$ & & \\
\hline \multicolumn{4}{|l|}{ RHS } \\
\hline BVECTOR & ROW1 & ROW2 & 155. \\
\hline BVECTOR & ROW3 & ROW4 & 1500. \\
\hline BVECTOR & ROW5 & ROW6 & 1860. \\
\hline BVECTOR & ROW7 & ROW8 & 1860 \\
\hline BVECTOR & ROW9 & & \\
\hline ENDATA & & & \\
\hline
\end{tabular}




\section{Appendix B}

\section{Sample of Computational}

\section{Results}

The summary of computational result for the example provided in appendix $A$ is given in the following two pages. Section 1 of the results deal with the sensitivity analysis of the variables. The main result, namely, the quantity of components loaded on different machines is obtained from section 2 . The variables which cutc the basic solution (denoted by BS in section 2 of the results) are the final solution for the example under consideration. 


\begin{tabular}{|c|c|c|c|c|c|}
\hline \multicolumn{6}{|c|}{ MPSCL EXECUTION } \\
\hline & PAGE & 266 & & & \\
\hline ONAME & JIT6 & & & & \\
\hline ROWS & & & & & \\
\hline N QUAN? & ITY & & & & \\
\hline L ROWI & & & & & \\
\hline L ROW2 & & & & & \\
\hline L ROW3 & & & & & \\
\hline L ROW4 & & & & & \\
\hline L ROW5 & & & & & \\
\hline L ROW6 & & & & & \\
\hline L ROW7 & & & & & \\
\hline L ROW8 & & & & & \\
\hline L ROW9 & & & & & \\
\hline COLUMS & X6H1 & ANTITY & 1.00000 & ROW1 & 1.00000 \\
\hline X6H1 & ROW5 & 3.50000 & & & \\
\hline $\mathrm{X} 6 \mathrm{H} 2$ & QUANTITY & 1.00000 & ROW1 & 1.00000 & \\
\hline $\mathrm{X} 6 \mathrm{H} 2$ & ROW6 & 3.20000 & & & \\
\hline $\mathrm{X} 6 \mathrm{H} 5$ & QUANTITY & 1.00000 & ROWi & 1.00000 & \\
\hline X6H5 & ROW9 & 3.10000 & & & \\
\hline X6El & QUANTITY & 1.00000 & ROW2 & 1.00000 & \\
\hline $\mathrm{X} 6 \mathrm{E} 1$ & ROW5 & 2.00000 & & & \\
\hline X6E3 & QUANTITY & 1.00000 & ROW2 & 1.00000 & \\
\hline $\mathrm{X} 6 \mathrm{E} 3$ & ROW7 & 2.40000 & & & \\
\hline X6E5 & QUANTITY & 1.00000 & ROW2 & 1.00000 & \\
\hline $\mathrm{X} 6 \mathrm{E} 5$ & ROW9 & 2.25000 & & & \\
\hline X6D1 & QUANTITY & 1.00000 & ROW3 & 1.00000 & \\
\hline X6D1 & ROW5 & 4.00000 & & & \\
\hline צ.5D3 & QUANTITY & 1.00000 & ROW3 & 1.00000 & \\
\hline X6D3 & ROW7 & 4.30000 & & & \\
\hline X6D4 & QUANTITY & 1.00000 & ROW3 & 1.00000 & \\
\hline X6D4 & ROW8 & 3.70000 & & & \\
\hline X6D5 & QUANTITY & 1.00000 & ROW3 & 1.00000 & \\
\hline X6D5 & ROW9 & 4.20000 & & & \\
\hline $\mathrm{X} 6 \mathrm{C} 1$ & QUANTITY & 1.00000 & ROW4 & 1.00000 & \\
\hline $\mathrm{X} 6 \mathrm{Cl}$ & ROW5 & 3.50000 & & & \\
\hline $\mathrm{X} 6 \mathrm{C} 3$ & QUANTITY & 1.00000 & ROW4 & 1.00000 & \\
\hline $\mathrm{X} 6 \mathrm{C} 3$ & ROW7 & 2.70000 & & & \\
\hline $\mathrm{X} 6 \mathrm{C} 4$ & QUANTITY & 1.00000 & ROW4 & 1.00000 & \\
\hline $\mathrm{X} 6 \mathrm{C} 4$ & ROW8 & 3.90000 & & & \\
\hline $\mathrm{X} 6 \mathrm{C5}$ & QUANTITY & 1.00000 & ROW4 & 1.00000 & \\
\hline $\mathrm{X} 6 \mathrm{C} 5$ & ROW9 & 3.00000 & & & \\
\hline
\end{tabular}


RHS

$\begin{array}{llrlr}\text { BVECTOR } & \text { ROW1 } & 531.00000 & \text { ROW2 } & 155.00000 \\ \text { BVECTOR } & \text { ROW3 } & 860.00000 & \text { ROW4 } & 1500.00000 \\ \text { BVECTOR } & \text { ROW5 } & 1860.00000 & \text { ROW6 } & 1860.00000 \\ \text { BVECTOR } & \text { ROW7 } & 1860.00000 & \text { ROW8 } & 1860.00000 \\ \text { BVECTOR } & \text { ROW9 } & 1860.00000 & & \end{array}$

ENDATA

OSECTION 1 - ROWS

- NUMBER ...ROW.. AT ...ACTIVITY... SLACK ACTIVITY ..LOWER LIMIT. ..UPPER LIMIT.

.DUAL ACTIVITY

\begin{tabular}{rlllccccc}
0 & 1 & QUANTITY & BS & 2908.98048 & $2908.98048-$ & NONE & NONE & 1.00000 \\
2 & ROW1 & UL & 531.00000 &. & NONE & 531.00000 & $1.00000-$ \\
3 & ROW2 & UL & 155.00000 &. & NONE & 155.00000 & $.50000-$ \\
4 & ROW3 & BS & 722.98048 & 137.01952 & NONE & 860.00000 &. \\
5 & ROW4 & UL & 1500.00000 & $\cdot$ & NONE & 1500.00000 & $.12500-$ \\
6 & ROW5 & UL & 1860.00000 &. & NONE & 1860.00000 & $.25000-$ \\
7 & ROW6 & BS & 1699.20000 & 160.80000 & NONE & 1860.00000 & $\cdot$ \\
8 & ROW7 & UL & 1860.00000 &. & NONE & 1860.00000 & $.32407-$ \\
9 & ROW8 & UL & 1860.00000 &. & NONE & 1860.00000 & $.27027-$ \\
10 & ROW9 & UL & 1860.00000 &. & NONE & 1860.00000 & $.29167-$ \\
1 MPSX/370 R 2.1.0 & \multicolumn{2}{l}{ MPSCL EXECUTION } & & & & PAGE
\end{tabular}

$1091 / 266$

OSECTION 2 - COLUMNS

- NUMBER .COLUMNS AT ...ACTIVITY... ..INPUT COST.. ..LOWER LIMIT. ..UPPER LIMIT. .REDUCED COST.

$$
0
$$

$11 \times 6 \mathrm{H} 1$

$12 \times 6 \mathrm{H} 2$

LL

BS

$13 \times 6 \mathrm{H} 5$

531.00000

1.00000

1.00000

$14 \times 6 \mathrm{E} 1$

LL

1.00000

$15 \times 6 E 3$

BS $\quad 155.00000$

1.00000

$16 \times 6 E 5$

LL

1.00000

1.00000

$17 \times 6 \mathrm{D} 1$

LL

BS

$18 \times 5 \mathrm{D} 3$

LL

$19 \times 6 \mathrm{D} 4$

$20 \times 6 \mathrm{D} 5$

BS

LL

$21 \times 6 \mathrm{Cl}$

BS

$22 \times 6 \mathrm{C} 3$

BS

$23 \times 6 \mathrm{C} 4$

LL

BS

$24 \times 6 \mathrm{C} 5$

1MPSX/370 R 2.1.0

$1191 / 266$

OEXIT - TIME $=0.00$

$\begin{array}{ll}\text { NONE } & .87500- \\ \text { NONE } & . \\ \text { NONE } & .90417- \\ \text { NONE } & . \\ \text { NONE } & .27778- \\ \text { NONE } & .15625- \\ \text { NONE } & . \\ \text { NONE } & .39352- \\ \text { NONE } & . \\ \text { NONE } & .22500- \\ \text { NONE } & . \\ \text { NONE } & . \\ \text { NONE } & .17905- \\ \text { NONE } & .\end{array}$

PAGE 